FEDERAL

RESERVE

BANK of

ST. LOUIS

\section{RESEARCH DIVISION} Working Paper Series

\title{
Differences in Subprime Loan Pricing Across Races and Neighborhoods
}

\author{
Andra C. Ghent, \\ Rubén Hernández-Murillo \\ and \\ Michael T. Owyang \\ Working Paper 2011-033C \\ https://doi.org/10.20955/wp.2011.033
}

March 2014

FEDERAL RESERVE BANK OF ST. LOUIS

Research Division

P.O. Box 442

St. Louis, MO 63166

The views expressed are those of the individual authors and do not necessarily reflect official positions of the Federal Reserve Bank of St. Louis, the Federal Reserve System, or the Board of Governors.

Federal Reserve Bank of St. Louis Working Papers are preliminary materials circulated to stimulate discussion and critical comment. References in publications to Federal Reserve Bank of St. Louis Working Papers (other than an acknowledgment that the writer has had access to unpublished material) should be cleared with the author or authors. 


\title{
Differences in Subprime Loan Pricing Across Races and Neighborhoods*
}

\author{
Andra C. Ghent, Rubén Hernández-Murillo, and Michael T. Owyang ${ }^{\dagger}$ \\ This draft: March 5, 2014.
}

\begin{abstract}
We investigate whether race and ethnicity influenced subprime loan pricing during 2005 , the peak of the subprime mortgage expansion. We combine loan-level data on the performance of non-prime securitized mortgages with individual- and neighborhoodlevel data on racial and ethnic characteristics for metropolitan areas in California and Florida. Using a model of rate determination that accounts for predicted loan performance, we evaluate the differences in subprime mortgage rates in terms of racial and ethnic groups and neighborhood characteristics. We find evidence of adverse pricing for blacks and Hispanics. The evidence of adverse pricing is strongest for purchase mortgages and mortgages originated by non-depository institutions.

Keywords: Fair Housing Act; Subprime Mortgages; Loan Performance; Discrimination.

JEL Codes: G21, J15, R23, C11
\end{abstract}

\footnotetext{
*Kristie M. Engemann, Christopher Martinek, and Kate Vermann provided research assistance. The views expressed herein are those of the authors and do not reflect the official positions of the Federal Reserve Bank of St. Louis, the Federal Reserve Board of Governors, or the Federal Reserve System. We thank Emek Basker, Jane Dokko, Morgane Laouenan, Joe Price, Stuart Rosenthal, Steve Ross, and Stephan Whitaker for helpful comments on an earlier draft. This paper has also benefited from the comments of workshop and seminar participants at Arizona State University, the Econometric Society European Meeting, the European Regional Science Association Meeting, the Federal Reserve Bank of New York, the Federal Reserve Bank of St. Louis, the Federal Reserve System Meeting on Microeconomic Analysis, Freddie Mac, Fordham University, the Mid-Year American Real Estate and Urban Economics Association meeting, the North American Summer Meeting of the Econometric Society, Pomona College, the Research Institute of Industrial Economics, Santa Clara University, the 10th Journees Louis-Andre Gerard-Varet Conference in Public Economics, the U.S. Census Bureau, the University of California (Berkeley), the University of Pennsylvania, the University of Toronto, the University of Wisconsin (Madison), and the Western Economics Association International Annual Meeting.

${ }^{\dagger}$ Ghent: W.P. Carey School of Business, Arizona State University; email aghent@asu.edu. HernándezMurillo: Research Division, Federal Reserve Bank of St. Louis; phone 314-444-8588; email: ruben.hernandez@stls.frb.org; Owyang: Research Division, Federal Reserve Bank of St. Louis; phone 314444-8558; email owyang@stls.frb.org.
} 


\section{Introduction}

Financial and technological innovation in underwriting processes has altered the manner through which discrimination may manifest in mortgage markets. Research on the role of income and race on consumer lending of mortgages originated prior to 1995, when mortgages were usually underwritten manually, found strong evidence that lenders were denying credit more frequently to black households than to white households with similar observable characteristics. ${ }^{1}$ After 1995, risk-based pricing of credit, rather than mere credit allocation, may have become an alternative channel for discrimination, particularly in the subprime market where lenders were much less likely to sell the loan to government-sponsored enterprises and were thus less constrained by firm cutoffs on variables such as loan-to-value ratios, loan size, and credit scores. In a world where lenders cope with credit risk by rationing credit, discrimination manifests itself primarily in loan denials. In contrast, when borrowers choose among several different sets of loan terms, each with a different price, minorities may be able to obtain credit but may have to pay a higher price for it.

Mortgage laws consider various notions of discrimination (see Ladd, 1998). Two broad classes of discriminatory behavior are disparate treatment and disparate impact. The former is manifest when lenders apply different pricing rules based on individual racial or neighborhood characteristics. The latter occurs when policies that do not explicitly take racial or neighborhood characteristics into account result in disparities among racial groups because race is correlated with other variables that may be used in underwriting, even when they are not necessarily good predictors of loan performance. Mortgage laws also prohibit lenders from denying loans or charging higher rates or fees to borrowers based on the racial composition of neighborhoods.

In this paper we use data on non-prime mortgages originated in 2005 in California and Florida to examine the influence of race and ethnicity on loan pricing across eight popular

\footnotetext{
${ }^{1}$ The seminal study is by Munnell, Browne, McEneaney, and Tootell (1996). Ross and Yinger (2002) provide a comprehensive overview and analysis of the literature surrounding that study; see also Duca and Rosenthal (1993), Ladd (1998), Bostic and Redfearn (2004), Elul (2004), and Yavas (2004).
} 
subprime mortgage products. We evaluate the presence of loan pricing disparities among minorities, relative to white borrowers, by analyzing the effect of race and neighborhood characteristics separately on: (1) the assessment by lenders of borrowers' risk profiles in an actuarial stage and (2) the interest rate determination in an underwriting stage. We use this approach (inspired from a proposal outlined in Ross and Yinger, 2002), to detect disparate treatment and disparate impact in loan pricing in a Bayesian framework of model selection. We also use this approach to detect adverse pricing differences in terms of the racial composition and income of neighborhoods. Additionally, we analyze whether blacks and Hispanics face more subtle forms of adverse loan pricing. For example, as suggested by Ross and Tootell (2004), lenders may require black and Hispanic borrowers to purchase private mortgage insurance when they would not require a white borrower with a similar risk profile to do so.

While we find adverse pricing effects in most of the products we examine, the economic magnitude of these effects is relatively small, when compared with other studies of loan pricing. In particular, for the most popular mortgage product, 30-year adjustable rate mortgages, we find that black and Hispanic borrowers face interest rates 12 and 29 basis points higher, respectively, than other borrowers. We also find evidence of income- or race-based neighborhood pricing disparities in seven of the eight mortgage products we analyze, including the most popular mortgage product, but these effects are considerably smaller: a 10-percentage-point increase in the neighborhood share of minorities is associated with, at worst, a 1.4 basis-point increase in interest rates. These effects are much smaller than the adverse pricing effects found in other lending markets, such as the peer-to-peer personal loan market analyzed in Pope and Sydnor (2011a) and Ravina (2012). The smaller magnitude of the effects in our study is likely due to a more stringent regulation of the mortgage market than the peer-to-peer personal lending market. A portion, but certainly not all, of the adverse pricing effects can be explained by differences in default and prepayment behavior by minorities and households in low-income neighborhoods or neighborhoods with a high 
proportion of minorities.

Our findings are consistent with anecdotal evidence regarding subprime loan pricing practices inferred from recent settlements of the U.S. Department of Justice against some of the largest subprime mortgage originators on allegations of unfair lending practices during the period from 2004 though 2009. ${ }^{2}$ The complaints by the Department of Justice alleged that black and Hispanic retail and wholesale borrowers "were charged higher fees and interest rates because of their race or national origin, and not because of the borrowers' creditworthiness or other objective criteria related to borrower risk." The Department of Justice also alleged that these lenders steered black and Hispanic borrowers into subprime mortgages when nonHispanic white borrowers with similar credit profiles received prime loans. ${ }^{3}$

The adverse pricing we describe may not necessarily reflect explicit discrimination or bias on the part of lenders, and in our analysis we offer some alternative explanations. For example, we find that borrower awareness of the mortgage market and differential access to mortgage market channels may influence some of the pricing differences that we uncover. More precisely, we find that the effect of race and neighborhood characteristics differs substantially by the type of loan (purchase or refinancing). There is much less evidence of adverse pricing in refinancings than in purchase mortgages. Because borrowers that refinance by definition have more experience with the mortgage market than borrowers taking out purchase mortgages, the difference in the results for purchase and refinance mortgages suggests that some of the adverse pricing facing minorities and households in traditionally underserved areas is due to differences in their ability to find the best possible rate rather than discrimination on the part of originators. Also, traditionally underserved borrowers may not have ready access or knowledge of different lenders' programs and the inexperienced may not actively seek out the best rate.

Furthermore, we also find that adverse pricing is more prevalent among non-depository

\footnotetext{
${ }^{2}$ See http://www.justice.gov/opa/pr/2012/July/12-dag-869.html and http://www.justice.gov/ opa/pr/2011/December/11-ag-1694.html.

${ }^{3}$ While the analysis of steering is beyond the scope of our paper, preliminary inspection of our data does not suggest evidence of this phenomenon.
} 
institutions. This result suggests that mortgage market channels play an important role in explaining the pricing disparities facing traditionally underserved borrowers. Mortgage brokers may be marketing expensive mortgages aggressively in minority neighborhoods. Conditional on receiving a mortgage from a depository institution, however, traditionally underserved households do not seem to experience pricing disparities, compared with white borrowers. We cannot, however, eliminate the possibility that the difference in our results for depository institutions is a result of greater regulatory scrutiny of depository institutions than of mortgage brokers.

For the reasons discussed above, and the anecdotal evidence notwithstanding, we are unable to decisively conclude that the adverse pricing we find is due to deliberate lender discrimination. Rather, the relatively small effects we find can perhaps be viewed as a victory for mortgage regulation since the 1980s and 1990s when there was substantial evidence of discrimination against minorities (see Ross and Yinger, 2002).

Our study is related to that of Haughwout, Mayer, and Tracy (2009) who examine 2/28 mortgages originated in August 2005 for the entire United States, but find no evidence of adverse loan pricing from race and ethnicity. Our paper, however, differs from that of Haughwout, Mayer, and Tracy (2009) in four important ways. First, our methodology allows us to detect both disparate impact and disparate treatment and to identify statistical adverse pricing. In contrast, the methodology of Haughwout, Mayer, and Tracy (2009) is aimed only at detecting disparate treatment, without exploring the source of potential disparities across racial groups. Second, in our approach we also emphasize detecting income- and race-based pricing differences across neighborhoods. Third, we analyze whether blacks and Hispanics face more subtle forms of rate disparities regarding prepayment penalty or private mortgage insurance requirements. Finally, we examine eight different mortgage products whereas Haughwout, Mayer, and Tracy confine their analysis to one category. Although the mortgage categories in both studies are not directly comparable (our product definitions emphasize the amortization term of the mortgage), we do not find evidence of racial disparities in 
adjustable rate mortgages with interest-only payments for the first two years, consistent with the findings of Haughwout, Mayer, and Tracy. However, we do find evidence of neighborhood income-based disparities in this category.

Our paper is also related to a recent audit study of adverse pricing in the mortgage market (Hanson, Hawley, Martin, and Liu, 2013). We view our results as complementary to those of Hanson, Hawley, Martin, and Liu, although the audit study provides more conclusive evidence of discrimination than our approach. The advantage of our approach relative to an audit study, however, is that we can detect adverse pricing due to disparate impact. Furthermore, it is difficult with audit studies to distinguish between adverse pricing due to statistical discrimination and adverse pricing that is unrelated to differences in loan performance across race or neighborhoods.

A much larger literature examines the effect of race and ethnicity on outcomes in other markets. Recent contributions attempting to detect statistical discrimination in particular include Altonji and Pierret (2001), Pope and Sydnor (2011b), and Chandra and Staiger (2010). Altonji and Pierret (2001) develop a method to test for the presence of statistical discrimination in the labor market. Pope and Sydnor (2011b) present an approach similar in spirit in ours but better suited to the labor market than the mortgage market. Chandra and Staiger (2010) examine racial disparities in health care and find that, to the extent they exist, they are not due to prejudice on the part of health care providers. ${ }^{4}$

In the next section, we describe the data and the matching algorithm. In Section 3, we present the model of rate determination and describe the estimation methodology. We present our results in Section 4, and analyze the potential sources of the adverse pricing in Section 5. We provide concluding remarks in Section 6.

\footnotetext{
${ }^{4}$ See Ross $(1996,1997,2000)$ and Ross and Yinger (2002) for a discussion of why the analog to Chandra and Staiger's approach in the mortgage market - the so-called default approach that Berkovec, Canner, Gabriel, and Hannan (1994) among others try to use - is inconclusive in the context of mortgages.
} 


\section{Data}

Our data are non-prime, private-label, securitized, first-lien mortgages originated in 2005 in California and Florida. We merge detailed data on the performance and terms of the loans from CoreLogic Information Solutions, Inc. (CL) with data on borrower income, borrower race, Census tract income, and Census tract racial composition obtained under the Home Mortgage Disclosure Act (HMDA). To match loans from CL with HMDA data, we use a matching algorithm similar to that of Haughwout, Mayer, and Tracy (2009) that uses lender names, dates of origination, and geographic location.

\subsection{Matching CL data with HMDA data}

The matching procedure considers first-lien loans with the same purpose (purchase or refinance) and occupancy status (owner-occupied). CL associates each loan with a 5-digit ZIP code, whereas HMDA loans are associated with Census tracts. To match ZIP codes with Census tracts we used Census ZIP Code Tabulation Areas (ZCTAs). ${ }^{5}$ We also used the geographic information systems software program Arcview to establish Census tract search areas associated with any given ZCTA as follows: For each loan in CL, we determined the smallest set of Census tracts that intersect with the associated ZCTA and we allowed for the union of the Census tracts in the intersection to extend over the geographic area defined by any given ZCTA.

Except for the use of ZCTAs, we followed Haughwout, Mayer, and Tracy's (2009) matching algorithm very closely. The procedure entails six stages that use the originator's name, the loan amount, and the origination dates to obtain the matches. The names are provided by the lenders themselves in the HMDA data, but not in the CL data. As a result, lender names in CL must be cleaned manually before the matching. Loan amounts are provided in dollars in CL, while they are provided in thousands of dollars in HMDA. Furthermore,

\footnotetext{
${ }^{5}$ ZCTAs are statistical entities developed by the Census to tabulate summary statistics from the 2000 Census for geographic areas that approximate the land area covered by each ZIP code.
} 
HMDA allows lenders to round up loan amounts to the nearest thousand dollars if the fraction equals or exceeds $\$ 500$. The dates are matched to within 5 business days if the CL dates are not imputed or to the same month if they are. ${ }^{6}$ A summary of the various stages is as follows:

- Stage 1 considers loans with matched originator names and uses the larger 4-digit ZCTA search areas. Loan amounts are matched allowing a difference of up to and including $\$ 1,000$.

- Stage 2 ignores originator names and uses 4-digit ZCTA search areas, as in stage 1.

- Stage 3 again considers originator names, but uses the smaller 5-digit ZCTA search areas. Loan amounts are matched allowing a difference of up to but not including $\$ 1,000$.

- Stage 4 is similar to stage 3 but ignores originator names.

- Stage 5 is similar to stage 1 but loan amounts are matched to within $2.5 \%$ of the CL amount.

- Stage 6 is similar to stage 2 but loan amounts are matched to within $2.5 \%$ of the CL amount.

At the conclusion of each stage, only one-to-one matches are kept and are removed from the datasets, while loans with multiple matches (either one CL loan to many HMDA loans, or many CL loans to one HMDA loan) are returned to the matching pool for the subsequent stages. We also applied various data checks to the final sample of loans, including dropping observations with missing or erroneous Fair Isaac Corporation (FICO) credit scores, as well as dropping observations with contract rates smaller than the reported HMDA spread of the loan's annual percentage rate with a Treasury security of comparable maturity.

\footnotetext{
${ }^{6} \mathrm{CL}$ origination dates are considered to be imputed if they are exactly two months before the first payment date.
} 


\subsection{Summary Statistics}

Tables 1 through 4 contain summary statistics on the loans in our sample by race and product type. Table 1 summarizes the counts of mortgages by product and race that were matched. We consider three racial or ethnic categories: Hispanics, non-Hispanic blacks, and the remainder (Other: non-Hispanic and non-blacks). ${ }^{7}$ We also consider the largest seven non-prime mortgage categories (which account for about 90 percent of all non-prime loans) and we include a category for the remainder. We define the categories according to the frequency distribution of the CL variable prod_type with an amortization period of 30 years.

We estimate our model separately for the different product types because the effect of loan characteristics on performance may differ according to the amortization structure. For example, a high loan-to-value (LTV) at origination is likely to be a much bigger contribution to default for loans that are interest-only for 10 years than for loans that start amortizing immediately. The categories are 2-year adjustable-rate mortgages (ARMs) (with interestonly payments for the first two years with full amortization over the remaining term), 3-year ARMs (with interest-only payments for the first three years with full amortization over the remaining term), 10-year ARMs (with interest-only payments for the first 10 years with full amortization over the remaining term), 10-year fixed-rate mortgages (FRMs) (with interestonly payments for the first 10 years with full amortization over the remaining term), 5-year ARMs (with interest-only payments for the first five years with full amortization over the remaining term), 30-year ARMs, and 30-year FRMs. We include all other loans in the remainder (Other) category.

We matched 281,180 purchase loans and 373,630 refinances, for a total of 654,810 mortgages. Hispanic borrowers obtained 101,576 purchase loans, almost 5 times the amount for black borrowers, and they obtained 96,441 refinancing loans, about 3 times the amount for

\footnotetext{
${ }^{7}$ HMDA distinguishes Hispanic borrowers with an ethnicity indicator and provides a separate variable to distinguish among races. Our definition of Hispanics therefore includes borrowers of any race, while our definition of blacks excludes Hispanic borrowers.
} 


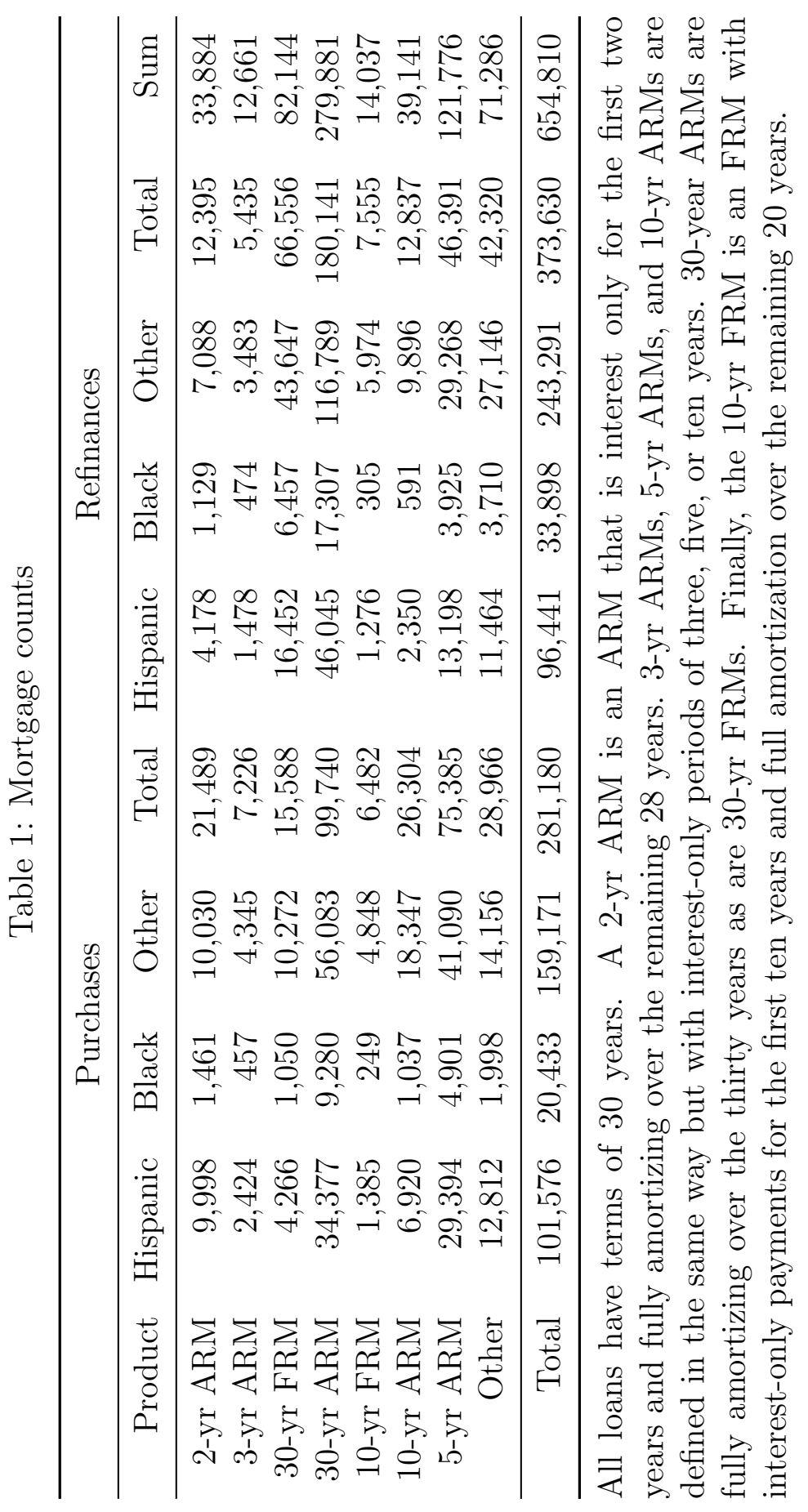


black borrowers. The most popular products for home purchases across all race categories were 2-year ARMs, 30-year ARMs, and 5-year ARMs. For refinances the most popular products also included 30-year FRMs. For comparison, Haughwout, Mayer, and Tracy (2009) matched only 2/28 ARMs using national data for August 2005 for a total of about 75,000 loans. Although Haughwout, Mayer, and Tracy do not specify how they defined 2/28 mortgages, in addition to prod_type, the CL variable first_rate, which contains the number of months before the first rate reset, is often used to define hybrid loans that exhibit an initial period of fixed interest rates; for $2 / 28 \mathrm{~s}$, first_rate $=24$. According to this definition, the hybrid 2/28 may include loans from all the ARM categories we analyzed.

Table 2 summarizes the proportion of loans by product and racial groups that (1) included prepayment penalties (PPPs), (2) required purchase of private mortgage insurance (PMI), and (3) required full documentation of income (Full Doc). Unconditionally, black and Hispanic borrowers face PPPs more frequently than other borrowers in all product categories. Also, both black and Hispanic borrowers tend to be required to obtain PMI more often than other borrowers for most mortgage products. Finally, black borrowers are required to provide full documentation of income slightly more often than Hispanics and other borrowers.

As Table 3 indicates, black and Hispanic borrowers tend to have lower FICO scores across most mortgage products (except that for 2-year ARMs Hispanic borrowers show a slightly higher FICO score than other borrowers). Black and Hispanic borrowers also tend to have mortgages with LTV ratios and higher debt-to-income (DTI) ratios. The variable Good Credit summarizes these differences; Good Credit takes a value of 1 if the borrower has a FICO score above the 50th percentile, the LTV ratio is at or below the 50th percentile, and the DTI ratio is at or below the 50th percentile. In summary, a smaller proportion of black and Hispanic borrowers exhibit good credit compared with other borrowers both for purchases and for refinances.

We thus do not see evidence of steering in our data, in the sense of a higher number 
Table 2: Prepayment Penalties, Private Mortgage Insurance, and Full Documentation

\begin{tabular}{|c|c|c|c|c|c|}
\hline Product & Race & $\mathrm{N}$ & PPP & PMI & FullDoc \\
\hline \multirow[t]{4}{*}{ 2-yr ARM } & Hispanic & 14,176 & 0.95 & 0.10 & 0.40 \\
\hline & Black & 2,590 & 0.94 & 0.11 & 0.53 \\
\hline & Other & 17,118 & 0.92 & 0.11 & 0.48 \\
\hline & Total & 33,884 & 0.94 & 0.11 & 0.45 \\
\hline \multirow[t]{4}{*}{ 3-yr ARM } & Hispanic & 3,902 & 0.74 & 0.10 & 0.46 \\
\hline & Black & 931 & 0.78 & 0.08 & 0.61 \\
\hline & Other & 7,828 & 0.61 & 0.07 & 0.50 \\
\hline & Total & 12,661 & 0.66 & 0.08 & 0.50 \\
\hline \multirow[t]{4}{*}{ 30-yr FRM } & Hispanic & 20,718 & 0.81 & 0.19 & 0.54 \\
\hline & Black & 7,507 & 0.88 & 0.22 & 0.66 \\
\hline & Other & 53,919 & 0.72 & 0.18 & 0.61 \\
\hline & Total & 82,144 & 0.76 & 0.19 & 0.59 \\
\hline \multirow[t]{4}{*}{ 30-yr ARM } & Hispanic & 80,422 & 0.92 & 0.19 & 0.36 \\
\hline & Black & 26,587 & 0.94 & 0.22 & 0.50 \\
\hline & Other & 172,872 & 0.87 & 0.18 & 0.41 \\
\hline & Total & 279,881 & 0.89 & 0.18 & 0.40 \\
\hline \multirow{4}{*}{ 10-yr FRM } & Hispanic & 2,661 & 0.33 & 0.05 & 0.29 \\
\hline & Black & 554 & 0.26 & 0.04 & 0.40 \\
\hline & Other & 10,822 & 0.27 & 0.03 & 0.39 \\
\hline & Total & 14,037 & 0.28 & 0.04 & 0.37 \\
\hline \multirow[t]{4}{*}{ 10-yr ARM } & Hispanic & 9,270 & 0.48 & 0.05 & 0.16 \\
\hline & Black & 1,628 & 0.43 & 0.07 & 0.26 \\
\hline & Other & 28,243 & 0.35 & 0.05 & 0.26 \\
\hline & Total & 39,141 & 0.38 & 0.05 & 0.24 \\
\hline \multirow[t]{4}{*}{ 5-yr ARM } & Hispanic & 42,592 & 0.90 & 0.17 & 0.42 \\
\hline & Black & 8,826 & 0.89 & 0.16 & 0.56 \\
\hline & Other & 70,358 & 0.81 & 0.15 & 0.52 \\
\hline & Total & 121,776 & 0.85 & 0.16 & 0.49 \\
\hline \multirow[t]{4}{*}{ Other } & Hispanic & 24,276 & 0.91 & 0.10 & 0.30 \\
\hline & Black & 5,708 & 0.92 & 0.12 & 0.45 \\
\hline & Other & 41,302 & 0.83 & 0.11 & 0.39 \\
\hline & Total & 71,286 & 0.87 & 0.11 & 0.37 \\
\hline
\end{tabular}

Prepay, PMI, and FullDoc indicate the shares of mortgages with prepayment penalties, private mortgage insurance, and full documentation, respectively. All loans have terms of 30 years. See Table 1 for product definitions. 
of high quality black and Hispanic borrowers than white borrowers in the subprime sector. The results in Table 3 in fact suggest the opposite. In every product category except $2 y r$ ARMs, where there is a slightly larger share of high quality Hispanic borrowers than Other borrowers, there is a larger share of high quality Other borrowers in the nonprime sector than blacks and Hispanics. While it is certainly possible that many borrowers in all product categories could have qualified for a mortgage in the prime sector, the evidence does not suggest that high quality borrowers were directed into the nonprime market by virtue of being a member of a minority group, but we did not explore the issue further.

Table 4 summarizes the loan amounts and contract interest rates. It also provides the average spread as provided to HMDA for loans that HMDA defines as high cost loans. Loan amounts for blacks and Hispanics are smaller than for other borrowers, and loan amounts for blacks are almost always smaller than for Hispanics. Black and Hispanic borrowers generally face higher contract interest rates than other borrowers. Finally, the difference in the rates paid by black and Hispanic borrowers relative to other borrowers is somewhat less pronounced in the spreads.

We focus on contract rates rather than the annual percentage rates (APRs). HMDA reports only the spread of the APR over a Treasury security of comparable maturity for high-cost loans (i.e., loans for which the spread is 300 basis points or more). Slightly half of the loans in our sample meet this threshold such that the variable is truncated. Furthermore, recovering points from the APR would require several assumptions. First, since a constant maturity 30 year Treasury series is not available during 2005, we would have to assume the calculation was performed using the 20 year Treasury. Originators compute the APR for each loan by assuming that the loan is held to maturity and that the loan adjusts to the initial fully indexed rate at origination (which is not necessarily equal to the contract rate). The originator is only required to report the APR rounded to the nearest one-eighth of 1 percent. Given this APR computation method, it is not possible to accurately identify from the APR the amount of points paid by the borrower. To understand the difficulty with recovering 
Table 3: Borrowers' Credit Characteristics

\begin{tabular}{|c|c|c|c|c|c|c|c|c|c|}
\hline & & & Good Credit & FI & & LTV & (\%) & DT & (\%) \\
\hline Product & Race & $\mathrm{N}$ & Share & Mean & SD & Mean & $\mathrm{SD}$ & Mean & $\mathrm{SD}$ \\
\hline 2-yr ARM & Hispanic & 14,176 & 0.14 & 660.18 & 46.71 & 81.18 & 7.31 & 32.79 & 18.27 \\
\hline & Black & 2,590 & 0.10 & 643.68 & 44.79 & 81.62 & 8.87 & 32.19 & 18.45 \\
\hline & Other & 17,118 & 0.12 & 651.55 & 48.11 & 81.12 & 8.34 & 32.01 & 18.70 \\
\hline & Total & 33,884 & 0.13 & 654.56 & 47.56 & 81.18 & 7.97 & 32.35 & 18.51 \\
\hline 3-yr ARM & Hispanic & 3,902 & 0.26 & 664.84 & 56.00 & 80.05 & 9.13 & 18.63 & 20.55 \\
\hline & Black & 931 & 0.20 & 649.86 & 57.44 & 80.07 & 9.94 & 18.30 & 20.42 \\
\hline & Other & 7,828 & 0.30 & 668.83 & 61.02 & 79.05 & 9.69 & 16.82 & 20.16 \\
\hline & Total & 12,661 & 0.28 & 666.21 & 59.46 & 79.43 & 9.55 & 17.49 & 20.32 \\
\hline 30-yr FRM & Hispanic & 20,718 & 0.24 & 649.75 & 64.63 & 69.64 & 15.96 & 22.99 & 21.13 \\
\hline & Black & 7,507 & 0.15 & 625.73 & 65.11 & 71.77 & 15.82 & 24.50 & 20.96 \\
\hline & Other & 53,919 & 0.31 & 657.27 & 70.42 & 70.18 & 16.23 & 20.59 & 20.72 \\
\hline & Total & 82,144 & 0.27 & 652.49 & 69.12 & 70.19 & 16.14 & 21.55 & 20.90 \\
\hline 30-yr ARM & Hispanic & 80,422 & 0.18 & 633.14 & 68.85 & 77.35 & 11.87 & 27.65 & 20.08 \\
\hline & Black & 26,587 & 0.10 & 608.35 & 65.16 & 78.48 & 12.07 & 28.56 & 20.07 \\
\hline & Other & 172,872 & 0.26 & 641.08 & 76.99 & 75.61 & 12.71 & 24.52 & 20.27 \\
\hline & Total & 279,881 & 0.22 & 635.69 & 74.28 & 76.38 & 12.45 & 25.80 & 20.26 \\
\hline 10-yr FRM & Hispanic & 2,661 & 0.59 & 709.43 & 48.10 & 72.44 & 13.36 & 14.36 & 19.13 \\
\hline & Black & 554 & 0.62 & 708.08 & 48.62 & 71.95 & 13.59 & 13.33 & 18.89 \\
\hline & Other & 10,822 & 0.66 & 720.15 & 48.88 & 69.94 & 14.66 & 13.54 & 18.63 \\
\hline & Total & 14,037 & 0.65 & 717.64 & 48.94 & 70.50 & 14.41 & 13.69 & 18.73 \\
\hline 10-yr ARM & Hispanic & 9,270 & 0.46 & 711.40 & 43.87 & 77.57 & 8.47 & 25.07 & 18.81 \\
\hline & Black & 1,628 & 0.42 & 704.44 & 46.41 & 77.40 & 9.11 & 26.22 & 18.55 \\
\hline & Other & 28,243 & 0.50 & 718.48 & 44.92 & 75.78 & 10.78 & 25.41 & 18.00 \\
\hline & Total & 39,141 & 0.49 & 716.22 & 44.90 & 76.27 & 10.24 & 25.36 & 18.22 \\
\hline 5-yr ARM & Hispanic & 42,592 & 0.17 & 667.16 & 49.71 & 80.25 & 7.77 & 33.67 & 18.12 \\
\hline & Black & 8,826 & 0.13 & 651.31 & 48.76 & 80.71 & 8.73 & 33.63 & 18.43 \\
\hline & Other & 70,358 & 0.19 & 666.37 & 53.11 & 79.55 & 9.15 & 32.07 & 18.93 \\
\hline & Total & 121,776 & 0.18 & 665.56 & 51.79 & 79.88 & 8.67 & 32.74 & 18.63 \\
\hline Other & Hispanic & 24,276 & 0.19 & 651.17 & 60.32 & 76.32 & 12.11 & 30.89 & 19.38 \\
\hline & Black & 5,708 & 0.15 & 630.64 & 61.77 & 75.96 & 13.16 & 30.96 & 19.30 \\
\hline & Other & 41,302 & 0.29 & 662.13 & 70.53 & 73.96 & 14.12 & 27.76 & 19.31 \\
\hline & Total & 71,286 & 0.25 & 655.88 & 67.14 & 74.92 & 13.44 & 29.08 & 19.39 \\
\hline
\end{tabular}

The variable Good Credit takes a value of 1 if the borrower has a FICO score above the 50th percentile, loan-to-value (LTV) ratio at or below the 50th percentile, and debt-to-income (DTI) ratio at or below the 50th percentile. All loans have terms of 30 years. See Table 1 for product definitions. 
Table 4: Loan Amount and Contract Interest Rate

\begin{tabular}{|c|c|c|c|c|c|c|c|c|}
\hline & & & \multicolumn{2}{|c|}{ Loan Amount $(\$)$} & \multicolumn{2}{|c|}{ Contract Rate (\%) } & \multicolumn{2}{|c|}{ HMDA Spread (\%) } \\
\hline Product & Race & $\mathrm{N}$ & Mean & $\mathrm{SD}$ & Mean & $\mathrm{SD}$ & Mean & $\mathrm{SD}$ \\
\hline \multirow[t]{4}{*}{ 2-yr ARM } & Hispanic & 14,176 & 316,103 & 119,105 & 6.73 & 0.72 & 4.45 & 0.66 \\
\hline & Black & 2,590 & 306,834 & 128,936 & 6.78 & 0.79 & 4.46 & 0.74 \\
\hline & Other & 17,118 & 339,721 & 139,265 & 6.74 & 0.77 & 4.42 & 0.72 \\
\hline & Total & 33,884 & 327,326 & 131,016 & 6.74 & 0.75 & 4.44 & 0.69 \\
\hline \multirow[t]{4}{*}{ 3-yr ARM } & Hispanic & 3,902 & 303,265 & 122,460 & 6.45 & 0.83 & 4.43 & 0.74 \\
\hline & Black & 931 & 288,766 & 145,428 & 6.53 & 0.86 & 4.50 & 0.75 \\
\hline & Other & 7,828 & 352,607 & 178,613 & 6.32 & 0.90 & 4.39 & 0.80 \\
\hline & Total & 12,661 & 332,706 & 162,949 & 6.37 & 0.88 & 4.42 & 0.78 \\
\hline \multirow[t]{4}{*}{ 30-yr FRM } & Hispanic & 20,718 & 235,716 & 125,729 & 6.68 & 0.84 & 4.28 & 0.90 \\
\hline & Black & 7,507 & 196,835 & 126,474 & 7.06 & 1.04 & 4.31 & 0.97 \\
\hline & Other & 53,919 & 264,165 & 184,481 & 6.68 & 0.93 & 4.22 & 0.93 \\
\hline & Total & 82,144 & 250,837 & 168,013 & 6.71 & 0.93 & 4.25 & 0.93 \\
\hline \multirow[t]{4}{*}{ 30-yr ARM } & Hispanic & 80,422 & 274,441 & 153,603 & 6.60 & 1.91 & 4.77 & 0.90 \\
\hline & Black & 26,587 & 236,264 & 149,899 & 7.15 & 1.72 & 5.02 & 0.98 \\
\hline & Other & 172,872 & 342,874 & 249,107 & 6.27 & 2.22 & 4.87 & 0.98 \\
\hline & Total & 279,881 & 313,083 & 220,862 & 6.45 & 2.11 & 4.85 & 0.96 \\
\hline \multirow[t]{4}{*}{ 10-yr FRM } & Hispanic & 2,661 & 325,813 & 169,578 & 6.32 & 0.54 & 4.54 & 0.83 \\
\hline & Black & 554 & 326,014 & 177,325 & 6.35 & 0.55 & 4.46 & 0.91 \\
\hline & Other & 10,822 & 390,752 & 245,285 & 6.20 & 0.47 & 4.32 & 0.86 \\
\hline & Total & 14,037 & 375,887 & 231,983 & 6.23 & 0.49 & 4.41 & 0.86 \\
\hline \multirow[t]{4}{*}{ 10-yr ARM } & Hispanic & 9,270 & 355,922 & 169,045 & 6.14 & 0.65 & 4.52 & 0.80 \\
\hline & Black & 1,628 & 356,047 & 200,023 & 6.15 & 0.72 & 4.53 & 0.83 \\
\hline & Other & 28,243 & 438,059 & 266,626 & 5.96 & 0.69 & 4.43 & 0.83 \\
\hline & Total & 39,141 & 415,195 & 247,145 & 6.01 & 0.68 & 4.48 & 0.82 \\
\hline \multirow[t]{4}{*}{ 5-yr ARM } & Hispanic & 42,592 & 320,851 & 131,012 & 6.63 & 0.76 & 4.53 & 0.77 \\
\hline & Black & 8,826 & 312,547 & 147,233 & 6.70 & 0.82 & 4.57 & 0.81 \\
\hline & Other & 70,358 & 355,918 & 178,554 & 6.51 & 0.81 & 4.42 & 0.79 \\
\hline & Total & 121,776 & 340,509 & 162,244 & 6.57 & 0.79 & 4.48 & 0.78 \\
\hline \multirow[t]{4}{*}{ Other } & Hispanic & 24,276 & 313,273 & 146,037 & 6.81 & 1.30 & 4.74 & 0.89 \\
\hline & Black & 5,708 & 292,839 & 160,319 & 6.99 & 1.39 & 4.90 & 0.97 \\
\hline & Other & 41,302 & 368,615 & 227,265 & 6.46 & 1.69 & 4.78 & 0.97 \\
\hline & Total & 71,286 & 343,701 & 200,317 & 6.62 & 1.55 & 4.78 & 0.94 \\
\hline
\end{tabular}

HMDA spread denotes the spread between the APR and the yield on a Treasury security of comparable maturity if the loan is a high-cost loan, defined as one for which the spread is 300 basis points or more. All loans have terms of 30 years. See Table 1 for product definitions. 
points from the APR, consider the following example: A 30 year ARM has an initial contract rate of $6.5 \%$ and the fully indexed rate at origination is $7.2 \%$. If the originator reports the APR as $7.125 \%$, it is possible that the borrower paid no points (unrounded APR of 7.133\%), paid 1 point (unrounded APR of $7.233 \%$ ), or received 1 point (unrounded APR of $7.034 \%$ ) although this last possibility is unlikely given originators' incentives. If the originator reports the APR as $7.25 \%$, we can infer only that the borrower paid one point (unrounded APR of $7.233 \%$ ) or two points (unrounded APR of $7.439 \%$ ). Thus, any measure of discount points derived from the APR is necessarily quite imprecise. Since most loans in our sample are prepaid long before maturity, the APR is a much noisier measure of the cost of borrowing than the initial contract rate. For example, the APR for a 30-year ARM with an interest rate that first resets five years after origination largely reflects the hypothetical reset rate (the rate the borrower is assumed to pay for the remaining 25 years on the loan) but a relatively small proportion of borrowers will still have the loan five years after origination. Furthermore, in preliminary analyses, we found much less variation across borrowers in the APR than in the contract rate on almost any dimension. Haughwout, Mayer, and Tracy (2009) also find that lenders seem to price risk primarily in the initial contract rate rather than subsequent reset rates.

Originators in our data appear to specialize in different product types. The top originators differ substantially across products. For instance, no originator appears in the set of top 10 originators in every product. ${ }^{8}$ Additional summary statistics of the variables used in the analysis are presented in Tables 12 to 14 of Appendix B.

\section{A Model of Mortgage Rate Determination}

In this section, we present a simple reduced-form model of mortgage rate determination derived from a test proposed by Ross and Yinger (2002, ch. 10). In the model, lenders charge a

\footnotetext{
${ }^{8}$ Confidentiality restrictions in our data agreement prevent us from presenting summary statistics regarding the number of originations by originator.
} 
rate based on the expected performance of the loan. Loan performance is judged by the expected probability that it produces adverse outcomes - for example, default or prepayment. Along the lines of Ladd (1998), who discusses various notions of mortgage discrimination in light of the relevant mortgage laws, we allow for the possibility that lenders may vary the rate charged based on variables used to identify two broad classes of discrimination: disparate treatment and disparate impact. The former is manifest in rate changes directly associated with race variables. The latter occurs when policies that do not explicitly take race into account result in disparities among racial groups because race is correlated with other nonracial variables that may be used in underwriting, even when they are not necessarily good predictors of loan performance. To this end, we allow loan performance to vary with racial and neighborhood characteristics. ${ }^{9}$ Furthermore, by including Census tract characteristics, namely, the tract's median family income relative to the median income of the metropolitan area and the percent of minority population, we can also analyze redlining - that is, whether lenders charge higher rates to borrowers living in low-income neighborhoods or in neighborhoods with high concentrations of minorities. ${ }^{10}$

The advantage of this approach is that it enables us to detect both disparate impact and disparate treatment, both of which are illegal. Disparate impact discrimination is illegal because lenders can easily mimic the effect of disparate treatment discrimination using disparate impact discrimination. That is, the lender can change the weight of various loan characteristics to discriminate against certain racial groups by taking advantage of correlations between race and non-racial borrower or loan characteristics that influence loan performance.

For example, suppose that a lender would like to charge black people more for their loans than white people. Suppose that the average FICO score of a black person is 100 points

\footnotetext{
${ }^{9}$ The median income of the metropolitan statistical area (MSA) or metropolitan division (MD), as applicable, is reported in HMDA. HUD determines whether lenders should use the MSA or the MD income and provides the relevant income to lenders. We refer to the MSA or MD as the metropolitan area.

${ }^{10}$ For a model of redlining in a credit-rationing framework, see Lang and Nakamura (1993). Collins and Margo (2001) explain the historical origins of race-based redlining in the US.
} 
lower than the average FICO score of a white person and that a 100-point increase in the FICO score lowers the probability of default by 10 percent. If the actuarially-fair reduction in the interest rate is 50 basis points for each 10 percent decrease in the default probability, we should observe that black people have interest rates on average 50 basis points higher than white people. After controlling for the effect of the FICO score on loan performance, we should not find a significant effect of black race on rates. However, if the lender wishes to discriminate against black people, the lender can increase the interest rate by, say, 200 basis points for each 100-point decrease in the FICO score.

We analyze adverse pricing as follows:

1. We randomly split the sample of loans for a particular mortgage product in two halves and estimate loan performance models on the first half (using default and prepayment as the adverse outcomes) using loan, individual, and Census tract characteristics including the minority status of the borrower, the income of the Census tract, and the racial composition of the Census tract. We label this the actuarial stage.

2. We then use the estimation outcomes from stage 1 to compute the predicted performance of the loans in the second half of the sample using loan and individual characteristics. The measure of predicted performance omits the minority status of the borrower, the Census tract income, and the racial composition of the Census tract.

3. Finally, we estimate a model with the loans from stage 2 using the actual interest rate as the dependent variable and the predicted probabilities of default and prepayment. We label this the underwriting stage.

\subsection{Empirical Framework}

To formalize, consider the following linear rate-setting equation:

$$
R_{n}=\beta_{0}+\beta_{p} \widehat{\mathbf{P}}_{n}+\beta_{z} \mathbf{z}_{n}+\gamma \odot \beta_{x} \mathbf{x}_{n}+e_{n}
$$


where $R_{n}$ is the rate charged for loan $n, \widehat{\mathbf{P}}_{n}$ is a $(\pi \times 1)$ vector of measures of predicted loan performance, $\mathbf{z}_{n}$ is a $\left(\kappa_{z} \times 1\right)$ vector of non-racial variables, and $e_{n} \sim N\left(0, \sigma^{2}\right)$. The $\left(\kappa_{x} \times 1\right)$ vector of treatment variables $\mathbf{x}_{n}$ includes a set of individual indicators (i.e., borrower race) and a set of neighborhood indicators (e.g., neighborhood racial composition). The symbol $\odot$ denotes the element-by-element (or Hadamard) product and the model indicator $\gamma$ is a vector of $0 \mathrm{~s}$ and $1 \mathrm{~s}$ with dimensions $\left(\kappa_{x} \times 1\right)$. Individual elements of $\gamma$ will determine the presence of disparate treatment or redlining in the rate: If $\gamma_{k}=1$, then $x_{k}$ is turned on, indicating the appropriate form of discrimination.

To estimate equation (1), we require the vector of predicted loan performance measures, $\widehat{\mathbf{P}}_{n}$. Loan performance data typically consist of binary measures (e.g., the loan defaults or is prepaid within two years) which would not be available at the time the rate is set. Instead, we construct a vector of expected loan performance, which is composed of the forecasted probability of loan default and the forecasted probability of prepayment. To construct these, we extract from the full sample of loans a subset of loans to use as an actuarial sample. From this sample, we estimate models of loan performance and use the resulting estimation to construct predicted performance for loans in a different underwriting sample on which we evaluate the presence of discrimination.

We partition the full set of loans into an $M$ loan actuarial sample and an $N$ loan underwriting sample. Let $\mathbf{P}_{m}$ represent the vector of $\pi$ different performance measures for loan $m$ from the actuarial sample. Let $\mathbf{q}_{m}$ represent the $\left(\kappa_{q} \times 1\right)$ vector of non-racial characteristics that affect loan performance (e.g., FICO score, LTV ratio), and let $\mathbf{w}_{m}$ represent the $\left(\kappa_{w} \times 1\right)$ vector of racial and neighborhood characteristics (black and Hispanic indicators, tract income, etc.) that may affect loan performance. For any loan $m$ in the actuarial sample, the probability that the event outlined by performance measure $i$ occurs (e.g., that loan $m$ defaults), $P_{i m}=1$, can be specified as a probit:

$$
\operatorname{Pr}\left[P_{i m}=1\right]=\Phi\left(\alpha_{i 0}+\alpha_{i q} \mathbf{q}_{m}+\alpha_{i w} \mathbf{w}_{m}\right)
$$


where the link function, $\Phi($.$) , is the standard normal cumulative distribution function (cdf)$ and $\alpha_{i}=\left[\alpha_{i 0}, \alpha_{i q}, \alpha_{i w}\right]$ are slope coefficients specific to the $i$ th performance measure. From (2), the predicted probabilities for loans from the underwriting subsample are computed as

$$
\widehat{P}_{i n}=\Phi\left(\widehat{\alpha}_{i 0}+\widehat{\alpha}_{i q} \mathbf{q}_{n}\right)
$$

where, again, $\Phi($.$) is the standard normal cdf, and \hat{\alpha}_{0}$ and $\hat{\alpha}_{q}$ represent the estimated parameters of equation (2). Note that the vector of race and neighborhood variables, $\mathbf{w}_{m}$, is excluded from the calculation of the actuarially consistent predicted loan performance measures. The use of these variables as predictors of loan performance is illegal; therefore, we must extract their effect from the loan performance model to properly assess the effect of other measures.

\subsection{Estimation}

The model could, in principle, be estimated with either classical or Bayesian methods; we use the latter for a number of reasons. First, in the Bayesian framework, directly incorporating the uncertainty in the predictions from the probit into the estimation of the rate equation is straightforward. Predicted performance in the rate equation (1) is a generated regressor (see Pagan, 1984) because it is computed from a model with unknown coefficients. In a classical environment, uncertainty for the two-step procedure can be incorporated by estimating the probit model using, for example, maximum likelihood. A bootstrap might then be employed to generate the standard errors which could be incorporated in the estimation of (1). In the Bayesian framework, the posterior distribution of the rate coefficients is computed considering the uncertainty in (2) directly. This is especially important given the nonlinearities in the predicted probabilities obtained from the probit.

Second, standard (classical) tests for discrimination might examine the statistical significance of the coefficients on the $\mathbf{x}_{n} \mathrm{~s}$ in alternative versions of equation (1), one which 
uses predicted performance as in equation (3). In the Bayesian environment, we can assess directly the probability that discrimination is present in the sample through the indicator, $\gamma_{k}$. Thus, estimated uncertainty about the binary indicator can be directly interpreted as the probability of discrimination. We favor this interpretation as it has a legal flavor, where the $\gamma_{k}$ can be interpreted as a verdict and the $\beta_{x k}$ can be interpreted as a degree of damage. Also, zeroing out any excluded indicator allows unbiased estimation of the magnitude of the included slopes.

Finally, the Bayesian framework allows for the imposition of prior information. While we impose relatively flat priors on the slope coefficients in both the actuarial and underwriting stages, we could impose relatively informative priors on the indicators. ${ }^{11}$ This is important because of our treatment of discrimination as a combination variable: a binary variable reflecting the presence of discrimination and a continuous variable reflecting the extent of the discrimination. In particular, if one wanted to hold a higher (or lower) standard for discrimination, one could choose a lower (or higher) prior probability of discrimination.

The posteriors used for inference are generated from the Gibbs sampler using two Metropolisin-Gibbs steps. The Gibbs sampler is a Markov Chain Monte Carlo technique that iteratively draws each parameter from its conditional distribution. The collection of draws converges to the full set of parameters' joint posterior. Inference is performed on a subset of draws, some of which are discarded to allow for convergence.

Our algorithm is a three-step procedure. In the first step, we draw the slope parameters of the probit. Second, after allowing for convergence, for each draw of $\alpha$, we compute our predicted performance measure, $\widehat{\mathbf{P}}_{n}$, conditional on the draw of $\alpha$. In the third step, for each $\widehat{\mathbf{P}}_{n}$, we then iteratively draw 1,500 samples of $\beta$ and $\gamma$, burning the first 1,000 to account for convergence. The first step is repeated 500 times after convergence is achieved. We store every tenth draw of $\beta$ and $\gamma$, which yields 500 draws of $\alpha$ and 25,000 draws of $\beta$ and $\gamma$, which

\footnotetext{
${ }^{11}$ The slope coefficients in both the rate equation and in the probit have mean zero normal priors; the variance of the innovations in the rate equation has an inverse gamma prior. The prior on the model indicator for the results outlined in the following sections are uniform.
} 
are then pooled. Note that the sampling algorithm described here accounts for the sampling uncertainty in $\alpha$ that would create the generated regressor problem in $\widehat{\mathbf{P}}_{n}$. The final result is a set of posterior distributions for $\alpha$ and $\beta$ and a set of model inclusion probabilities for each of the $\mathbf{x}_{n}$ s. Details of the sampling methods, including the specifications for the priors and the posterior draws, are included in Appendix A.

\subsection{Caveats on the Estimation}

The most important limitation of the estimation is that the data set might not provide all the information available to the originator when determining the loan performance or the underwriting of the mortgage contract. This problem affects most empirical studies of discrimination. The consequence, of course, is that the racial or neighborhood indicators may capture some of the significance of the omitted variables. In this case, the disparities across racial and ethnic groups and across neighborhoods that we calculate should be interpreted as upper bounds of the effects.

A related econometric problem is that some of the variables we used may suffer from measurement error. In particular, the borrower's income may have been misreported upwardly during the period we analyzed, and consequently variables such as the DTI ratio may have been mis-measured in cases where full documentation was not required at the time of origination.

Finally, we have assumed that the interest rate is not a determinant of the loan performance. Relaxing this assumption would increase the complexity of the estimation procedure. We conjecture that omitting the interest rate in the loan performance equations would bias the estimated coefficients of the racial and neighborhood indicators in the rate equation only if the interest rate and the treatment variables are not orthogonal, in which case, we again would interpret our results as providing upper bounds for the pricing disparities across racial or ethnic groups and across neighborhoods. 


\section{Results}

In this section we discuss the results from estimating the model outlined in the previous section. We focus on describing any disparities in loan pricing across racial or ethnic groups and across neighborhoods, and we delay interpretation of these disparities to section 5 .

\subsection{Loan Performance}

As discussed in the previous section, we randomly divide the sample for each mortgage product in half. We use the first half to form the actuarial sample and estimate the probit model for two measures of loan performance: default within 2 years and prepayment within 2 years of closing. ${ }^{12}$

Tables 5 and 6 present the results from the loan performance models using the actuarial sample. Table 5 shows the results for the default measure, and Table 6 shows the results for the prepayment measure. ${ }^{13}$ The coefficients in the tables represent the medians of the posterior distributions of the parameters. We shade out cases in which 0 is contained in the 90 percent coverage interval, indicating that a variable is not a statistically important determinant of the corresponding performance measure. The results from the loan performance models indicate that standard measures of credit worthiness, such as FICO scores, LTV ratios, and, to a lesser extent, DTI ratios are important determinants of both default and prepayment. The coefficients on the refinance dummy variable indicate that refinances are associated with lower default and higher prepayment. Borrowers with 30-year FRMs and 30-year ARMs are more likely to default in Florida than in California, while most mortgage products are less likely to be prepaid in Florida than in California. Black and Hispanic

\footnotetext{
${ }^{12}$ We consider a loan in default if the CL variable MBA_STAT takes a value of 9 (90-days or more delinquent), $\mathrm{F}$ (in foreclosure), or R (REO). We consider a loan prepaid if the loan leaves the database or has an MBA_STAT of 0 in a particular month and the MBA_STAT variable does not take a value of 6 (60-days delinquent), 9, F, or $\mathrm{R}$ in the month before the loan leaves the database. To keep our model parsimonious, we do not construct loan performance measures for other horizons; see Demyanyk (2009) for evidence on the large proportion of subprime loans that terminate within two or three years of origination.

${ }^{13}$ Models of mortgage performance often include a prepayment option variable (i.e., the spread between the rate on the loan at origination and the current market rate). We include dummies for the month of origination in the probit models and in the rate equation to control for the spread.
} 


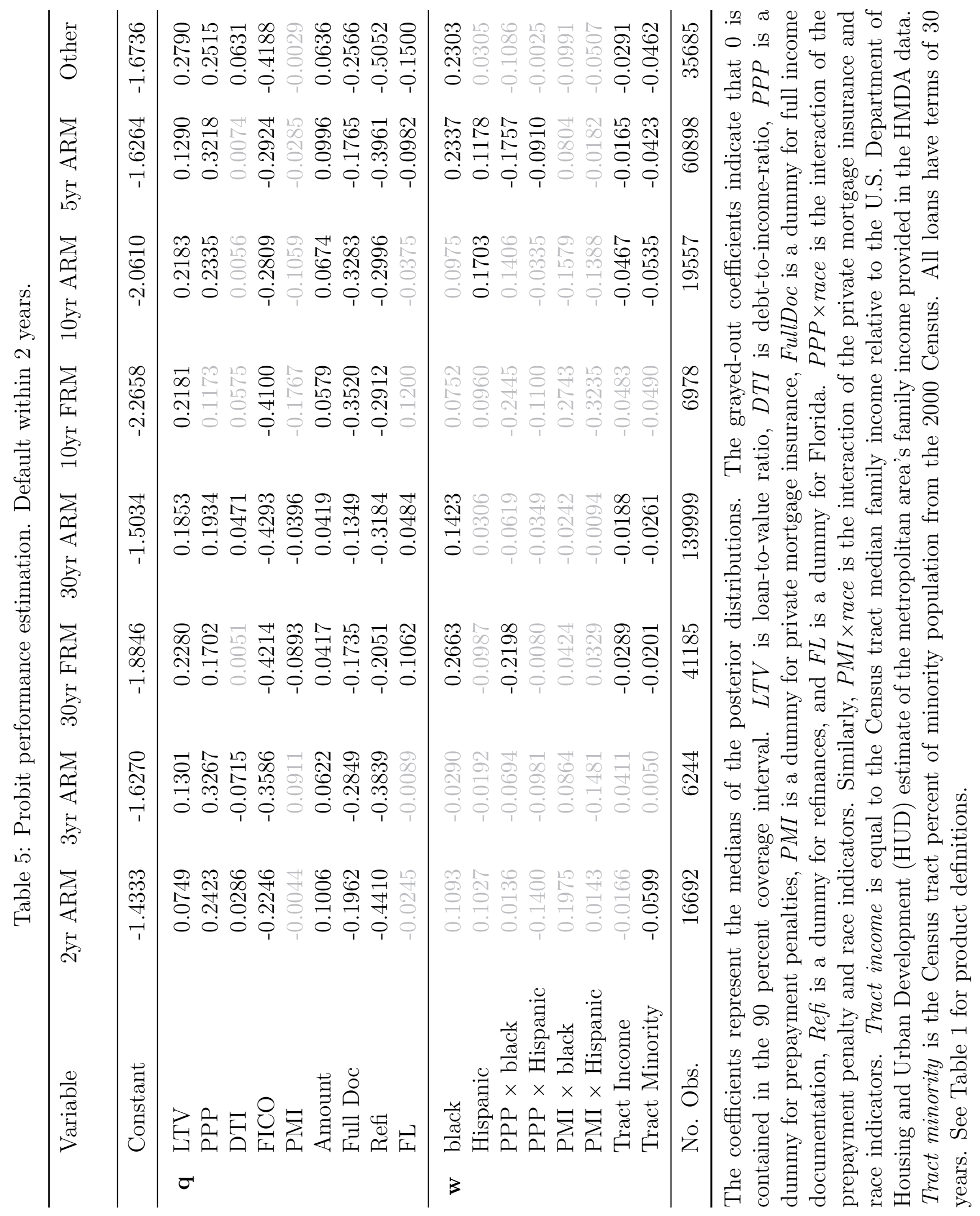




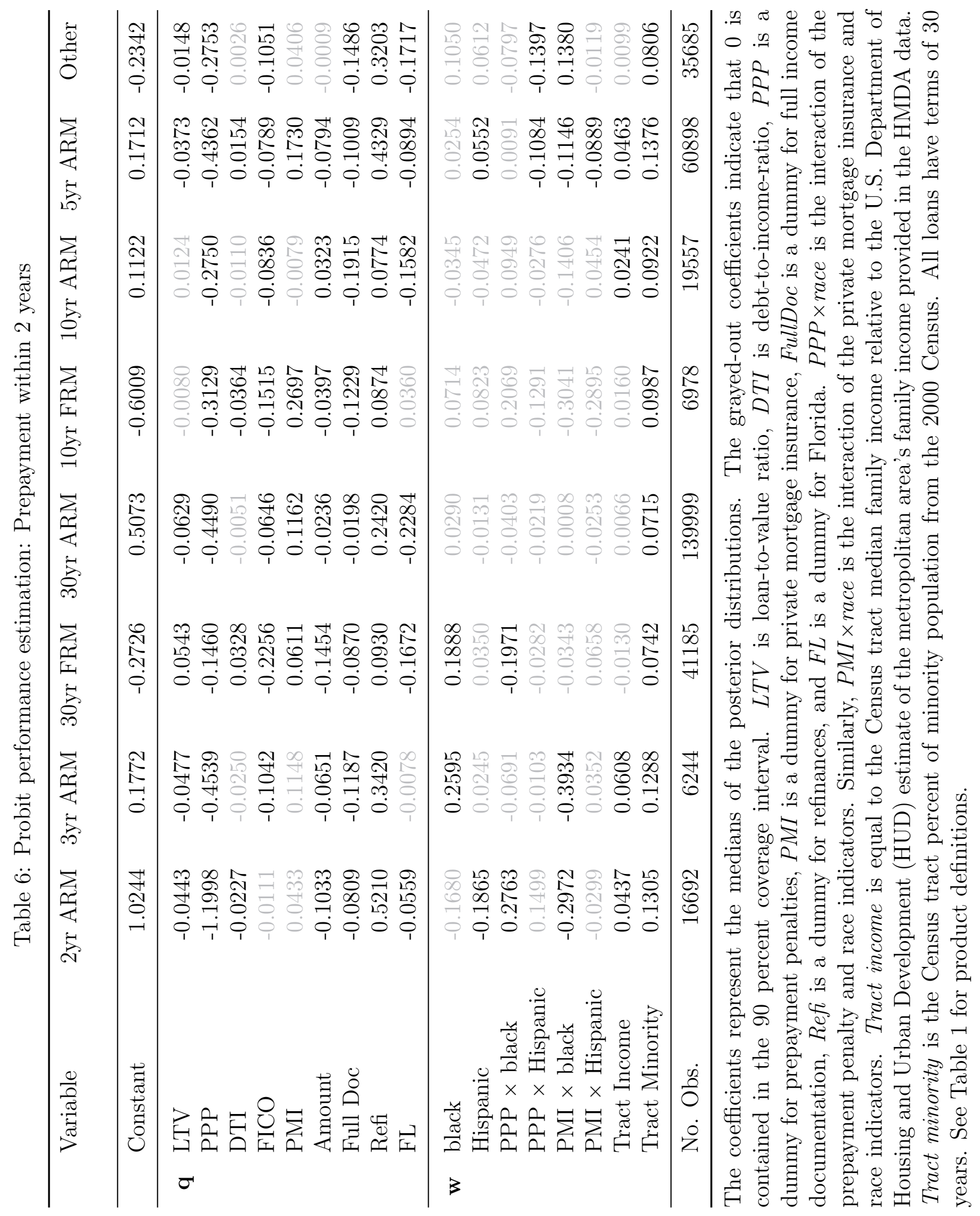


borrowers are more likely to default in five of the eight mortgage product categories. PPPs for black and Hispanics appear to be associated with lower default rates for some products; they have a negative impact on prepayment in some mortgage products. Higher tract income (measured as Census tract median family income relative to the metropolitan area) and a higher tract share of minority population are associated with both lower default probability and higher prepayment probability across most product categories.

\subsection{Loan Pricing}

Table 7 presents the estimation of the rate-setting equation, equation (1). The estimated coefficients are separated in four panels corresponding to the constant; the measures of predicted performance, $\hat{P}$; the non-racial variables, $z$; and the race and neighborhood variables, $x$. As in Tables 5 and 6 , the coefficients represent the medians of the posterior distribution and the shaded out coefficients in the $\hat{P}$ and $z$ panels indicate that 0 is contained in the 90 percent coverage interval.

The coefficients associated with the treatment variables in the $x$ panel also represent the medians of the posterior distributions, conditional on the corresponding inclusion variable $\gamma$, for cases in which the model inclusion probability (that the value of $\gamma$ in equation (1) is equal to 1) exceeds 90 percent, which indicates the presence of adverse pricing.

We do not report estimated coefficients of the race and neighborhood variables, $x$, if the estimation procedure does not indicate that the corresponding $x$ variable should be turned on at least 90 percent of the time. This omission is deliberate because the coefficients would, in this case, be meaningless, as the procedure indicates that these variables should not be included in the model. We do, however, report the model inclusion probabilities for adverse pricing, $\operatorname{Pr}(\gamma=1)$, in Table 8. In this table, the bold entries correspond to the coefficients reported in Table 7 .

The results from Table 7 indicate that both measures of forecasted performance (default within 2 years and prepayment within 2 years) have a positive impact on rate determination. 


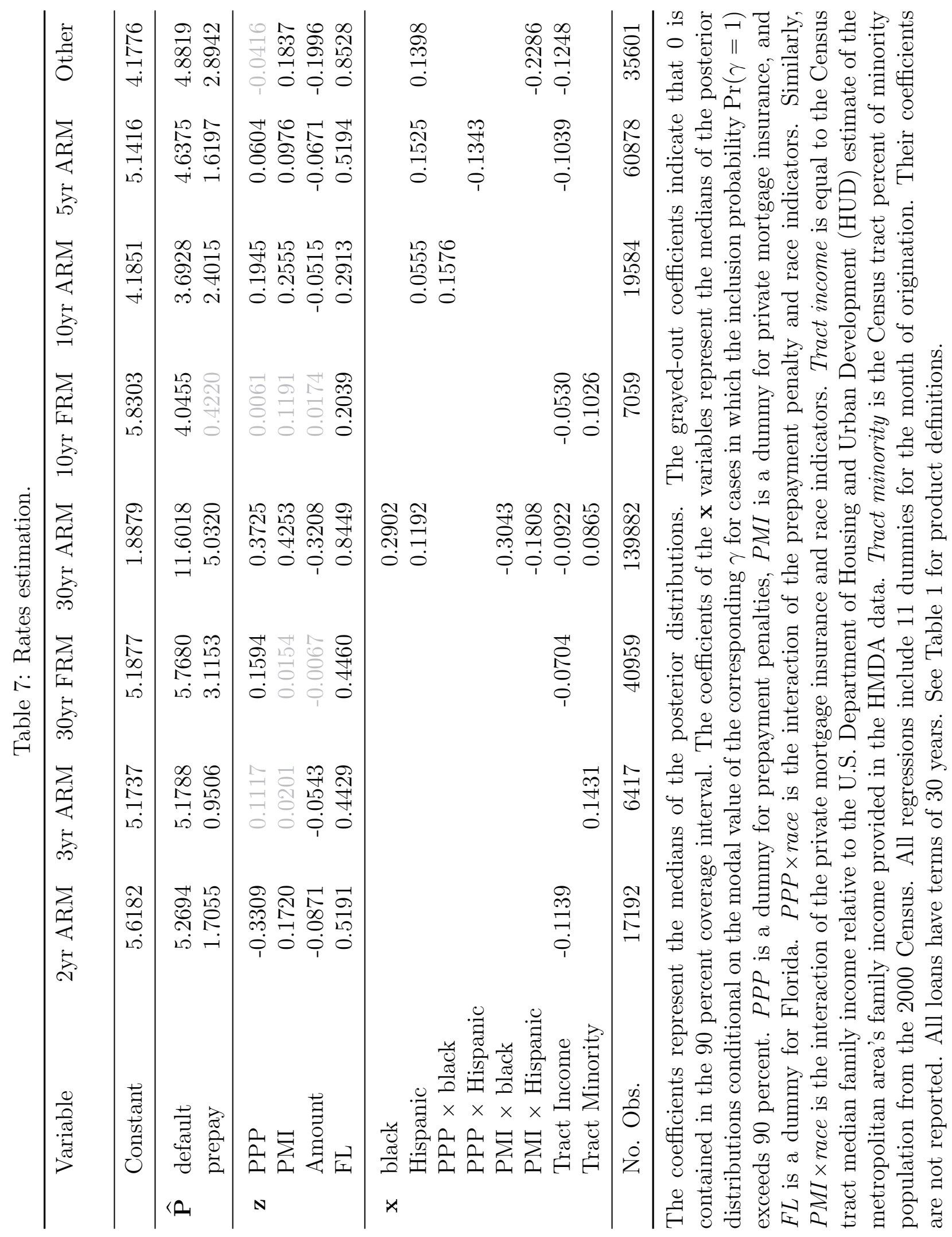


The increase in the rate from a 1-percentage-point increase in the probability of default ranges from 4 to 12 basis points depending on the product. The increase in the rate from a 1-percentage-point increase in the probability of prepayment ranges from 1 to 5 basis points depending on the product.

PPPs are associated with higher rates in four of the mortgage product categories but have a negative association with rates in 2-year ARMs. Similarly, the PMI requirement has a positive association with rates in five of the eight mortgage products. Higher loan amounts reduce interest rates in most categories, and loans in Florida exhibit higher interest rates than in California in all mortgage categories.

Table 7 indicates that the black and Hispanic indicators have a positive effect on interest rates for 30-year ARMs. Black borrowers face rates about 29 basis points higher for this product while Hispanic borrowers face rates about 12 basis points than non-Black, nonHispanic borrowers. Furthermore, Hispanic borrowers face rates 6 basis points higher in the 10-year ARM category, 15 basis points higher in the 5-year ARM category, and 14 basis points higher in the "Other" category. Table 8 illustrates that for the "Other" category, a direct impact from the black indicator is a borderline case in which the model inclusion probability does not meet the threshold we set to indicate adverse pricing; the inclusion probability is $82 \%$.

The purchase of PMI among black and Hispanic borrowers lowers interest rates in 30year ARMs while the purchase of PMI lowers the interest rate for Hispanics in the "Other" category. ${ }^{14}$

A higher tract income is associated with lower interest rates in 2-year ARMs, 30-year FRMs, 30-year ARMs, 10-year FRMs, 5-year ARMs, and the "Other" category indicating income-based neighborhood rate disparities. Income in the regression is measured relative to the median income in the metropolitan area such that the interpretation of the results in Table 7 is that a household that lives in a Census tract with double the median income

\footnotetext{
${ }^{14} \mathrm{~A}$ limitation of our study is that we do not know the size of the prepayment penalty, and it remains possible that there are differences in prepayment penalties across race that we do not observe.
} 
of the income in the metropolitan area enjoys a 2-year ARM mortgage rate that is 11 basis points lower than a borrower who lives in a Census tract with median income equal to that of the metropolitan area.

A higher share of minorities in a Census tract leads to higher interest rates for 3-year ARMs, 30-year ARMs, and 10-year FRMs, although the effects are rather small. The increase in the rate from moving from a Census tract with no minorities to a Census tract with only minorities (a 100-percentage-points increase) ranges from 9 to 14 basis points. The race-based neighborhood rate disparities occur despite our finding that a higher minority share in a neighborhood actually reduces the probability of default (see Table 5). The high correlation between the share of minorities and tract income likely makes it difficult for both variables to be statistically relevant at the same time in most categories in all products except 30-year ARMs where we have substantially more data. We see some evidence of racebased neighborhood disparities in 10-year ARMs and in 5-year ARMs; the model inclusion probabilities are 78 percent and 77 percent which are slightly below our threshold of 90 percent as shown in Table 8.

Our results for the 2-year ARM category are consistent with the findings of Haughwout, Mayer, and Tracy (2009) for 2/28 mortgages. However, we find evidence of income-based neighborhood disparities in this category; Haughwout, Mayer, and Tracy (2009) do not include Census tract income in their specification although they do include controls for the home ownership and unemployment rates. Haughwout, Mayer, and Tracy find evidence that a high share of blacks or Hispanics in a neighborhood actually reduces the interest rate; we do not find this in our specification. Since our datasets differ, we cannot determine whether the difference in our findings is due to differences in the sample, the procedure used to detect adverse pricing, or differences in the product definition. 


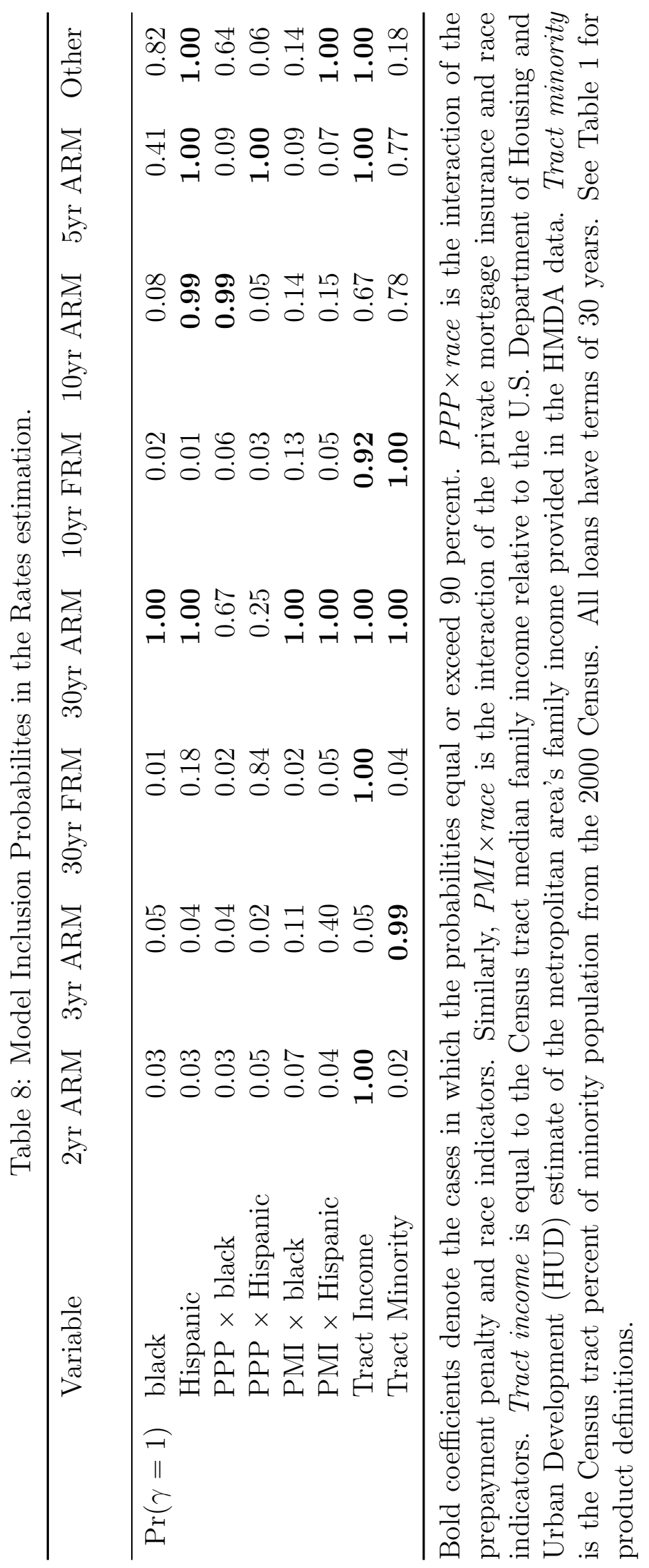




\subsection{Economic Magnitude of Effects}

To understand how the adverse pricing effects we find translate into increases in payments, we consider a loan for $\$ 300,000$ with full amortization over 30 years and a base interest rate of $6.5 \%$, resulting in monthly payments of $\$ 1,896.20$. Such a loan is representative of the 30 year ARM category, for example (see Tables 12 to 14 of Appendix B). First, consider the direct effect of race or ethnicity on interest rates. The upper bound for the effect of adverse pricing based on the borrower's race that is not due to differences in prepayment or default behavior is 29 basis points, the adverse pricing faced by blacks in 30-year ARMs. An increase in the interest rate of 29 basis points translates into an increase in the monthly payment of $\$ 57.57$ or $3 \%$ of the payment. Second, consider the effect on the interest rate because of adverse race-based neighborhood disparities. The upper bound on the increase in the interest rate from a 10-percentage-point increase in the neighborhood share of minority population is 1.4 basis points, in the 3-year ARM category. Such an increase in the interest rate raises the monthly payment by $\$ 2.77$ or $0.15 \%$ of the payment.

It is instructive to compare the magnitudes of the adverse pricing in the subprime market with what Pope and Sydnor (2011a) and Ravina (2012) report in the peer-to-peer personal loan market. Pope and Sydnor (2011a) find that blacks face interest rates that are 60 to 80 basis points higher than whites while Ravina (2012) finds that black borrowers pay 148 to 183 basis points more for their loans than whites. The smaller degree of adverse pricing in the subprime market is likely due to more stringent regulation of the mortgage market than the unregulated peer-to-peer loan market.

\subsection{Robustness}

We perform several robustness exercises. We first add controls for metropolitan areas in the rate equation. We also consider a three year horizon for default and prepayment rather than the two year window in our benchmark. We also estimate the model with an indicator variable for whether the loan was originated by a depository institution. The results in these 
cases are similar to those from estimating our benchmark specification. In the benchmark specification, we do not include borrower income directly in our performance estimation since (back-end) DTI is highly correlated with a function of the mortgage amount and income. We have estimated the model with borrower income and the results are quite similar to the benchmark case, however; these results are available upon request.

\section{Understanding the Sources of Adverse Pricing}

In this section we interpret the disparities in loan pricing we characterized in the previous section in terms of the language and notions of discrimination used in mortgage laws. Additionally, we provide alternative interpretations that do not involve discrimination or bias against minorities and discuss the situations in which they can arise.

\subsection{Disparate Impact vs. Disparate Treatment}

The evaluation of adverse pricing outlined in Section 3 focused on distinguishing whether disparities in loan rates across racial and neighborhood characteristics manifested in the loan pricing equation. The procedure assumed that lenders took into account differences in loan performance across ethnic groups and then controlled for that effect to prevent statistical adverse pricing.

Identifying disparate impact discrimination requires determining whether disparities across racial groups or neighborhood characteristics are the result of uniform underwriting standards across groups that, nevertheless, allow for embedded bias which negatively affects certain groups. In the context of our evaluation procedure, one way to approach this possibility is to calculate measures of predicted performance that are based on actuarial estimations that ignore the predictive content of individual race and neighborhood characteristics and allow non-racial credit risk indicators to carry all the predictive content. In particular, consider 
estimating the following model of loan performance:

$$
\operatorname{Pr}\left[P_{i m}=1\right]=\Phi\left(\alpha_{i 0}+\alpha_{i q} \mathbf{q}_{m}\right) .
$$

Constructing the implied measure of forecasted performance with parameter estimates $\breve{\alpha}_{0}$ and $\check{\alpha}_{q}$ yields

$$
\check{P}_{i n}=\Phi\left(\check{\alpha}_{i 0}+\check{\alpha}_{i q} \mathbf{q}_{n}\right) .
$$

Disparate impact discrimination can then be assessed if any disparities in the $x$ variables, initially identified in the rate equation with the predicted performance defined in equations (2) and (3), are reduced or eliminated once we use the measure of performance in equation (5) that allows for bias in the probit coefficients.

We studied this possibility and found no evidence of disparate impact. In other words, allowing for bias in the estimated coefficients of loan performance did not seem to eliminate the disparities in the rate equation. In the interest of brevity, we do not report additional tables. Results are available upon request.

\subsection{Differences in Search and Mortgage Market Channels}

In this subsection, we explore whether adverse pricing is pervasive in the mortgage market or whether it is specific to certain kinds of borrowers or certain types of originators. Our goal is to ascertain whether the adverse pricing we detect is because of discrimination on the part of originators or whether some effects stem from differences in mortgage market access or borrower search behavior. To this end, we estimate the model using different subsamples in our data. Table 9 summarizes these findings.

\subsubsection{Purchases vs. refinances}

First, we explore whether the effect is equally strong in purchase and refinance mortgages to understand whether the borrower's experience in the mortgage market affects the likelihood 
of adverse pricing. There may be differences across race in the ability of borrowers to effectively compare across mortgage offerings. Such differences may arise because minority borrowers are more likely to be the first generation to be home owners and such do not benefit from intergenerational transfers of mortgage market knowledge. To the extent that purchase mortgages have a higher share of first time home buyers, who have less mortgage market savvy than other borrowers, a finding of greater adverse pricing in the sample of only purchase mortgages likely indicates that some of the adverse pricing we find is not due to discrimination on the part of lenders per se. Rather, such a finding would indicate that the disparities arise because minority borrowers that lack mortgage market experience search less intensively or less effectively than white households.

When we estimate (1) using only data from purchase mortgages, we find a greater degree of adverse pricing for blacks and Hispanics as well as households in low income neighborhoods or minority neighborhoods than in our benchmark specification. In our benchmark specification, the upper bound on the effect of race on the rate was 29 basis points (in our 30-year ARM category). In the purchase only sample, the upper bound for the effect of race on the upper bound for the effect of race on the rate is 54 points (in the 30 -year ARM category). The magnitudes of the adverse pricing in other products and for the neighborhood characteristics are also higher in the purchase only sample than in the full sample.

In contrast, when we estimate (1) using only data from refinancings, we find adverse pricing for blacks in only one product category (30 year ARMs) and higher prices for households residing in low income neighborhoods in only two products (30-year ARMs and 5-year ARMs). We find no evidence of higher prices for Hispanics, or for households living in neighborhoods with large minority shares in the refinance only sample.

\subsubsection{Top 10 originators}

We next use data only from the top 10 originators in the product category to control for originator-specific fixed effects. The top 10 originators account for at least $40 \%$ of originations 
in all products except 10-year FRMs where they account for only $10 \%$ of originations. When we include fixed effects for the originator, we see less evidence of adverse pricing than in our benchmark specification. Although we continue to see adverse pricing against blacks in the 30-year ARM category, we see evidence of adverse pricing for Hispanics in only the 10-year ARM category. By comparison, in our benchmark specification, we find evidence of adverse pricing for Hispanics in 30-year ARMs, 10-year ARMs, 5-year ARMs, and the Other category.

We also see somewhat less evidence of income-based or racial-based neighborhood disparities after controlling for originator fixed effects. In our benchmark specification, we found evidence of higher prices in low-income neighborhoods in all products except 3-year ARMs and 10-year ARMs as well as higher prices in neighborhoods with large shares of minorities in 3-year ARMs, 30-year ARMs, and 10-year ARMs. When we include originator fixed effects, we no longer see evidence of income-based neighborhood disparities in 30-year FRMs or 10year FRMs and find evidence of race-based neighborhood disparities only in 3-year ARMs with 2-year ARM borrowers in predominantly minority neighborhoods actually seeing lower rates.

To explore whether the difference in our results once we include originator fixed effects

are due in part to a smaller sample, we also estimate (1) with only the data from the top 10 originators but without originator fixed effects. The results regarding the effect of race on rates are quite similar to our benchmark specification. However, we see no evidence of income-based neighborhood disparities in the 10-year FRM category in this sample likely because the sample size is quite small at only 710 originations.

\subsubsection{Depository vs. non-depository institutions}

Finally, we explore whether the adverse pricing is present for loans originated by a depository institution, which we identify by the regulator reported to in HMDA, or is specific to loans originated by non-depository institutions. Non-depository institutions are likely to 
be mortgage brokers. We estimate the rate equation first on only depository institutions. Depository institutions account for only $23 \%$ of 2-year ARM originations but between $40 \%$ and $60 \%$ of originations in the other product categories.

When we restrict our attention to depository institutions, we find much less evidence of adverse pricing based on either race or neighborhood characteristics. In the 30-year ARM categories, blacks face rates 18 basis points higher while Hispanics face rates 11 basis points higher in the 5-year ARM category. We see evidence of income-based neighborhood disparities only in the 5-year ARM category and no evidence of race-based neighborhood disparities.

In the sample of loans originated by non-depository institutions, we see adverse pricing more frequently and the magnitudes are larger for the adverse pricing due to race. For example, in the 30-year ARM category, blacks face rates 44 basis points higher in the nondepository institution sample while the adverse pricing faced by blacks in the 30-year ARM category was only 29 basis points in the full sample.

\subsection{Statistical Adverse Pricing}

We next consider whether the adverse pricing we identify can be explained by a higher default or prepayment propensity by minority households and households that live in certain kinds of neighborhoods.

To identify adverse pricing due to differences in default or prepayment, the predicted loan performance used in underwriting (3) is rewritten to include the vector of treatment variables, $\mathbf{w}_{m}$. In this case, adverse pricing causes a change in the loan's predicted performance through a difference in the probability of, say, default. To capture this possibility, we can compute an alternative measure of predicted performance that accounts for the effect of racial and neighborhood characteristics:

$$
\widetilde{P}_{i n}=\Phi\left(\widehat{\alpha}_{i 0}+\widehat{\alpha}_{i q} \mathbf{q}_{n}+\widehat{\alpha}_{i w} \mathbf{w}_{m}\right) .
$$




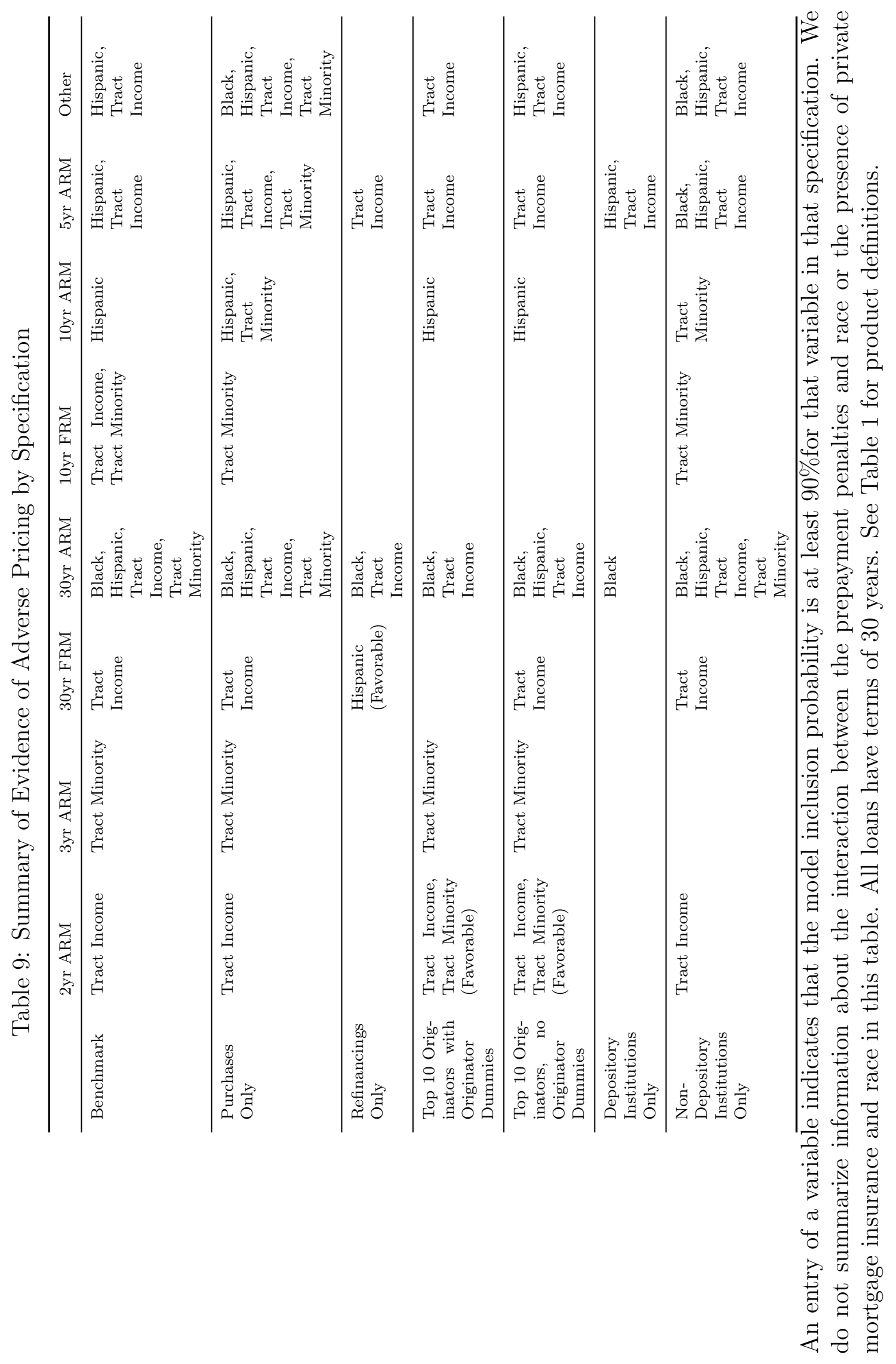


The model identifies statistical adverse pricing via a nonlinear, borrower-specific, effect on loan performance based on racial and tract characteristics. Any residual adverse pricing is then identified as a uniform direct effect of race on interest rates. That is, we analyze this form of discrimination by comparing price-setting models in which lenders use race to predict loan performance (statistical adverse pricing) and models in which race affects interest rates directly (disparate treatment).

To accomplish this, we modify the rate equation to account for the change in expected loan performance. We augment the rate equation with two vectors of model indicator dummies, $\gamma$ and $\delta$ :

$$
R_{n}=\beta_{0}+\beta_{p}\left(\left(\mathbf{1}_{\pi}-\delta\right) \odot \widehat{\mathbf{P}}_{n}+\delta \odot \widetilde{\mathbf{P}}_{n}\right)+\beta_{z} \mathbf{z}_{n}+\gamma \odot \beta_{x} \mathbf{x}_{n}+e_{n}
$$

where $\mathbf{1}_{\pi}$ is a vector of 1 s with dimension $(\pi \times 1)$. The model indicators $\gamma$ and $\delta$ are vectors of 0 s and $1 \mathrm{~s}$ with dimensions $\left(\kappa_{x} \times 1\right)$ and $(\pi \times 1)$, respectively. Individual elements of $\gamma$ will determine the presence of disparate pricing in the rate: If $\gamma_{k}=1$ then $\mathbf{x}_{k}$ is turned on. Because we restrict $\beta_{p}$ to be the same in both the $\widehat{\mathbf{P}}_{n}$ and $\widetilde{\mathbf{P}}_{n}$ terms, the $\delta$ s can be thought of as a model selection variable that determines the presence of statistical adverse pricing; that is, if $\delta_{i}=1$ then $\widetilde{\mathbf{P}}_{i}$ is turned on.

To estimate this specification, we modify our algorithm as follows. In the first step, we draw the slope parameters of the probit. Second, after allowing for convergence, for each draw of $\alpha$, we compute two predicted performance measures, $\widehat{\mathbf{P}}_{n}$ and $\widetilde{\mathbf{P}}_{n}$, conditional on the draw of $\alpha$. In the third step, for each $\widehat{\mathbf{P}}_{n}$ and $\widetilde{\mathbf{P}}_{n}$ combination, we then iteratively draw 1,500 samples of $\beta, \delta$, and $\gamma$, burning the first 1,000 to account for convergence. The remainder of our algorithm is the same as for our benchmark specification.

Table 10 presents the estimation of the rate-setting equation augmented to account for differences in loan performance across our variables of interest, equation (7). The estimated coefficients are separated in four panels corresponding to the constant; the measures of predicted performance, $\hat{P}$; the non-racial variables, $z$; and the race and neighborhood variables, 
$x$. As in Table 7, the coefficients represent the medians of the posterior distribution and the shaded out coefficients in the $\hat{P}$ and $z$ panels indicate that 0 is contained in the 90 percent coverage interval. The bold italicized coefficients in the $\hat{P}$ panel additionally indicate that the model inclusion probability (the probability that the value of $\delta$ in equation (7) is equal to 1) exceeds 90 percent, which indicates the presence of statistical adverse pricing.

The coefficients associated with the treatment variables in the $x$ panel also represent the medians of the posterior distributions, conditional on the corresponding inclusion variable $\gamma$, for cases in which the model inclusion probability (that the value of $\gamma$ in equation (7) is equal to 1) exceeds 90 percent, which indicates the presence of adverse pricing that cannot be explained by higher default or prepayment rates.

The estimates in Table 7 show that we see statistical adverse pricing in 30-year FRMs and 5-year ARMs. As a result, the model inclusion probabilities for $\gamma$ in these products are no longer above our threshold for many variables. We continue to see adverse pricing effects that cannot be explained by higher default or prepayment probabilities in 2-year ARMs, 30-year ARMs, 5-year ARMs, and the Other category.

The results indicate that disparities in loan pricing for minorities cannot be explained entirely by the effect of race or neighborhood characteristics on the probabilities of either default or prepayment. In particular, the model that allows lenders to use information on race and neighborhood characteristics to forecast default or prepayment probabilities (a practice that is prohibited) indicates that, in some of the most popular mortgage products, in addition to facing statistical adverse pricing, minorities and individuals in lower-income neighborhoods seem to face adverse pricing effects from lender practices that are unrelated to predicting loan performance.

It is important to note that, according to Tables 5 and 6 , both tract income and tract minority share are important determinants of both default and prepayment for most product categories, while race is an important determinant of default for most products but an important determinant of prepayment for only some products. These results suggest that 


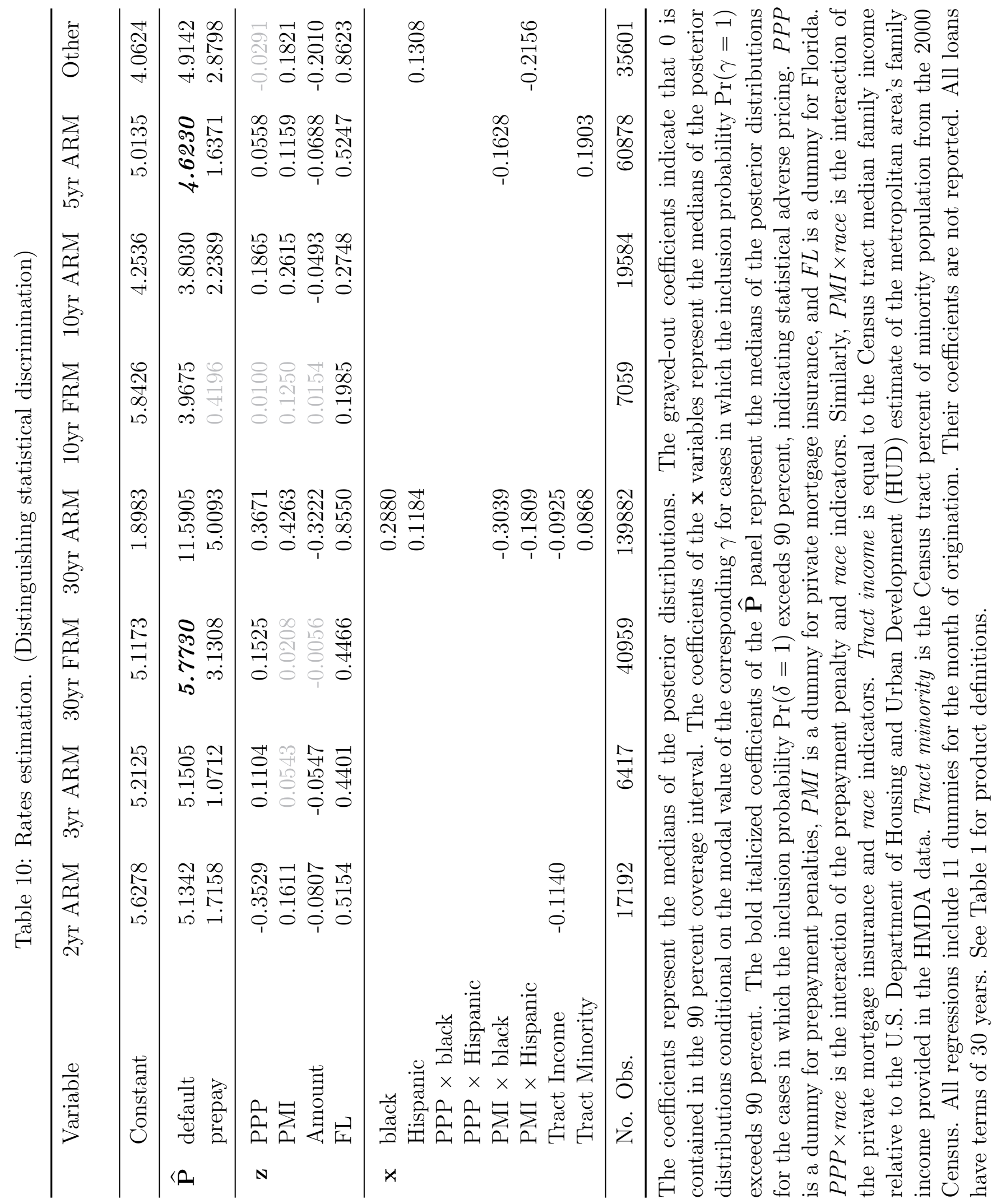


statistical adverse pricing on prepayment largely reflects the predictive power of neighborhood characteristics for this measure of loan performance.

Finally, it bears repeating that our procedure aims to detect racial and neighborhoodbased disparities that cannot be explained by higher default or prepayment probabilities. It is important to make this distinction because fair lending laws are quite clear that both statistical and disparate treatment discrimination against minorities is illegal. Redlining on the basis of the racial composition of neighborhoods is also illegal. While income-based redlining is not explicitly illegal, many federal housing policies (e.g., the affordable housing goals of the GSEs and the Community Reinvestment Act) are aimed at reducing the prevalence of this practice.

\subsection{Caveats on the Interpretation}

A common caveat in empirical studies of discrimination is that interpreting estimation results as lender discrimination requires the researchers to accurately control for all information that may be observable to the originator at the time of underwriting - clearly, an impossible task, as no available data set can possibly provide all information. However, by clearly considering the different notions of discrimination contemplated in mortgage laws to analyze loan pricing disparities, we provide a starting point to study the potential sources of these disparities and how best to address them.

While it is true that we can never hope to have access to all information available to the originator (such as a borrower's entire credit history, as opposed to only the credit score at the time of closing), an important limitation of our study is that we do not observe the points (origination fees) paid by minorities at closing time. While it is possible that some discrimination is manifested in differences in closing costs, it is unlikely that the main source of the adverse pricing that we find in terms of origination rates is because households in lower income neighborhoods, households in neighborhoods with higher concentrations of racial minorities, or racial minorities, pay lower origination fees in exchange for higher 
contract interest rates. While there is reason to believe that minorities have lower wealth than comparable white households, such that they might rationally choose to pay less up front, the existing empirical evidence (Woodward, 2008; Woodward and Hall, 2010) indicates that minorities pay more in closing costs than comparable white households. Furthermore, there is no clear reason to believe that, after controlling for race and income, households in low income neighborhoods have less wealth and thus choose to pay fewer points. Our main specification controls for borrower race and includes borrower income via the payment to income ratio. In robustness exercises we also include borrower income in levels and find very similar results to our benchmark specification.

\subsection{Additional Dimensions of Mortgage Discrimination}

Our analysis leaves out many aspects of discrimination that have been traditionally analyzed in previous literature. In this paper we focus on describing adverse loan pricing in subprime mortgages because of the limitations imposed by the availability of data.

First, our data set contains no information on the prime mortgage market. Consequently, in the present study we do not consider several interesting issues related to the prime market, such as loan pricing differentials between minority borrowers and white borrowers in the prime market or the segmentation of low-income or minority borrowers into prime and subprime markets. ${ }^{15}$ Similarly, the analysis of potential steering of low-income or minority borrowers from the prime to the subprime market is an important question that we cannot address with the available data.

Second, although the HMDA data contains information on loan applications and denials, this information cannot be used to study discrimination on the extensive margin. Clearly, the HMDA data set does not provide information on the possibilities that may have been available to the borrower at the time of applying for a mortgage, as borrowers are not uniquely identified in the HMDA data. In fact, outside of specialized borrower surveys, no

\footnotetext{
${ }^{15}$ See Nichols, Pennington-Cross, and Yezer (2005) for a discussion of segmentation of the subprime and prime mortgage markets.
} 
such information is available in any of the commonly used mortgage data sets. Similarly, the merged data does not allow us to study a borrower's choice among the available subprime products.

\section{Conclusions}

In this paper we examine the effect of race and ethnicity on the pricing of subprime mortgages in California and Florida during 2005. We estimate a reduced-form model of mortgage rate determination in which the lender takes into account the predicted loan performance when making the rate-setting decision. We assess the effect of race and ethnicity, as well as the effect of neighborhood characteristics, both in the loan performance evaluation and in the lender's rate decision.

In contrast to previous studies of the subprime market, we find evidence of various forms of adverse pricing against black or Hispanic borrowers. In our analysis, we provide alternative interpretations for identifying the sources of these disparities, including various notions of discrimination contemplated in U.S. mortgage laws, as well as explanations that do not involve discrimination, such as differences in borrower behavior and access to market channels.

The magnitude of the effects we describe is relatively small compared with other studies of loan pricing. First, the adverse pricing effects lead to rate increases ranging from 5 to 29 basis points. For a typical loan in our sample, an increase in the interest rate of 29 basis points translates into an increase in the monthly payment of $\$ 57.57$. Second, we also find that to the extent that black and Hispanic borrowers live in low-income neighborhoods and in neighborhoods with high proportions of minority borrowers, they may face an additional increase in their rates, but the effects are substantially smaller. The increase in the rate from a 10-percentage-point increase in the neighborhood minority population share ranges from 0.9 to 1.4 basis points, which translates into an increase in the monthly payment of 
$\$ 2.77$. We also find that, for minority borrowers, the purchase of private mortgage insurance seems to be associated with obtaining lower interest rates. Finally, a portion, but not all, of the adverse pricing effects that we calculate can be explained by differences default or prepayment in loans to minority borrowers or households in low-income neighborhoods or neighborhoods with a high proportion of minorities.

A limitation of our study is that we cannot infer whether adverse pricing exists in the prime market. To the extent that the subprime market relies more heavily on manual underwriting than the prime market, it is possible that automated underwriting has eliminated discrimination and redlining in the prime market. However, we cannot confirm or dispel this notion without a direct examination of the prime market.

We also argue that some of the adverse pricing we describe is likely due to factors other than an explicit intent on the part of lenders to discriminate against racial minorities. In our analysis, we consider the following explanations: a lack of competition in the mortgage market in certain neighborhoods, mortgage market segmentation, and reduced search efforts or a lower ability of certain borrowers to compare across sets of loan terms. ${ }^{16}$ Indeed, we find the strongest evidence of adverse pricing in purchase mortgages where borrowers have less experience in the mortgage market.

We conclude that the relatively small degree of adverse pricing we find can perhaps be viewed as a victory for mortgage regulation since the 1980s and 1990s, periods for which the literature has provided ample evidence of discrimination against minorities.

\section{References}

Altonji, Joseph G. and Charles R. Pierret, 2001. "Employer Learning and Statistical Discrimination." Quarterly Journal of Economics 116:1, 313-350.

Berkovec, James A., Glenn B. Canner, Stuart A. Gabriel, and Timothy H. Hannan,

\footnotetext{
${ }^{16}$ Indeed, Woodward and Hall (2010) find evidence that minorities pay more in closing costs, a finding they attribute to consumer confusion.
} 
1994. "Race, Redlining, and Residential Mortgage Loan Performance." Journal of Real Estate Finance and Economics 9, 263-294.

Bostic, Raphael W. and Christian L. Redfearn, 2004. "Review of The Color of Credit: Mortgage Discrimination, Research Methodology, and Fair Lending Enforcement." Journal of Regional Science 44:1, 162-165.

Chandra, Amitabh and Douglas O. Staiger, 2010. "Identifying Provider Prejudice in Healthcare." NBER Working Paper 16382.

Collins, William J. and Robert A. Margo, 2001. "Race and Home Ownership: A Century Long View." Explorations in Economic History 38, 68-92.

Demyanyk, Yuliya, 2009. "Quick Exits of Subprime Mortgages." Federal Reserve Bank of St. Louis Review, March-April, 79-94.

Duca, John V. and Stuart S. Rosenthal, 1993. "Borrowing Constraints, Household Debt, and Racial Discrimination in Loan Markets." Journal of Financial Intermediation 3, 77-103.

Elul, Ronel, 2004. "Review of The Color of Credit: Mortgage Discrimination, Research Methodology, and Fair Lending Enforcement." Economic Journal 114:499, F541-F544.

Hanson, Andrew, Zackary Hawley, Hal Martin, and Bo Liu, 2013. "Experimental Tests for Discrimination by Mortgage Loan Originators." Manuscript, Marquette University.

Haughwout, Andrew; Mayer, Christopher; and Tracy, Joseph, 2009. "Subprime Mortgage Pricing: The Impact of Race, Ethnicity, and Gender on the Cost of Borrowing." BrookingsWharton Papers on Urban Affairs, 33-63.

Holmes, Chris C. and Held, Leonhard, 2006. "Bayesian Auxiliary Variable Models for Binary and Multinomial regression." Bayesian Analysis 1, 145-168. 
Ladd, Helen F., 1998. "Evidence of Discrimination in Mortgage Lending." Journal of Economic Perspectives 12:2, 41-62.

Lang, William W. and Nakamura, Leonard I., 1993. "A Model of Redlining." Journal of Urban Economics 33, 223-234.

Munnell, Alicia H.; Browne, Lynn E.; McEneaney, James; and Tootell, Geoffrey M.B., 1996. "Mortgage Lending in Boston: Interpreting HMDA Data." American Economic Review $86: 1,25-53$.

Nichols, Joseph; Pennington-Cross, Anthony; and Yezer, Anthony, 2005. "Borrower SelfSelection, Underwriting Costs, and Subprime Mortgage Credit Supply." Journal of Real Estate Finance and Economics 30:2, 197-219.

Pagan, Adrian, 1984. "Econometric Issues in the Analysis of Regressions with Generated Regressors." International Economic Review 25, 221-247.

Pope, Devin G. and Sydnor, Justin R., 2011a. "What's in a Picture? Evidence of Discrimination from Prosper.com." Journal of Human Resources 46:1, 53-92.

Pope, Devin G. and Sydnor, Justin R., 2011b. "Implementing Anti-Discrimination Policies in Statistical Profiling Models." American Economic Journal: Economic Policy 3, 206231.

Ravina, Enrichetta, 2012. "Love and Loans: The Effect of Beauty and Personal Characteristics in Credit Markets." Manuscript, Columbia University.

Ross, Stephen L., 1996. "Mortgage Lending Discrimination and Racial Differences in Loan Default." Journal of Housing Research 7:1, 117-126.

Ross, Stephen L., 1997. "Mortgage Lending Discrimination and Racial Differences in Loan Default: A Simulation Approach." Journal of Housing Research 8:2, 277-297. 
Ross, Stephen L., 2000. "Mortgage Lending, Sample Selection and Default." Real Estate Economics, 28:4, 581-621.

Ross, Stephen L. and Tootell, Geoffrey M.B., 2004. "Redlining, the Community Reinvestment Act, and Private Mortgage Insurance." Journal of Urban Economics 55, 278-297.

Ross, Stephen L. and Yinger, John, 2002. The Color of Credit: Mortgage Discrimination, Research Methodology, and Fair-Lending Enforcement. MIT Press: Cambridge, Massachusetts.

Tanner Martin A. and Wong, Wing Hung, 1987. "The Calculation of Posterior Distributions by Data Augmentation." Journal of the American Statistical Association 82, 528-540.

Troughton, Paul T. and Godsill, Simon J., 1997. "A reversible jump sampler for autoregressive time series, employing full conditionals to achieve efficient model space moves." Technical Report CUED/F-INFENG/TR.304, Cambridge University Engineering Department.

Yavas, Abdullah, 2004. "Review." Journal of Economic Literature 42:1, 190-191.

Woodward, Susan E., 2008. A Study of Closing Costs for FHA Mortgages. U.S. Department of Housing and Urban Development, Office of Policy Development and Research.

Woodward, Susan E. and Hall, Robert E., 2010. "Consumer Confusion in the Mortgage Market: Evidence of Less than a Perfectly Transparent and Competitive Market." American Economic Review: Papers and Proceedings 100, 511-515. 


\section{Appendix}

\section{A: Estimation Details}

This appendix describes the Bayesian methods used to estimate the model in sections 3 and 5.3. The model is estimated with an iterative technique - the Gibbs sampler - which requires a prior. For the slope parameters in the rate equation (7), we assume a normal prior. The innovation variance of the rate equation has an inverse gamma prior. Each of the model indicators has a flat prior. The hyper-parameters for the prior distributions are shown in Table 11.

Table 11: Priors for Estimation

\begin{tabular}{ccc}
\hline Parameter & Prior Distribution & Hyperparameters \\
\hline$\alpha_{i}$ & $N\left(\mathbf{a}_{0}, \mathbf{A}_{0}\right)$ & $\mathbf{a}_{0}=\mathbf{0}_{1+\kappa_{q}+\kappa_{w}} ; \mathbf{A}_{0}=\mathbf{I}_{1+\kappa_{q}+\kappa_{w}}$ \\
$\beta_{-p}$ & $N\left(\mathbf{b}_{0}, \mathbf{B}_{0}\right)$ & $\mathbf{b}_{0}=\mathbf{0}_{1+\kappa_{x}+\kappa_{z}} ; \mathbf{B}_{0}=\mathbf{I}_{1+\kappa_{x}+\kappa_{z}}$ \\
$\beta_{p}$ & $N\left(\mathbf{d}_{0}, \mathbf{D}_{0}\right)$ & $\mathbf{d}_{0}=\mathbf{0}_{\pi} ; \mathbf{D}_{0}=\mathbf{I}_{\pi}$ \\
$\sigma^{-2}$ & $\Gamma\left(\frac{\nu_{0}}{2}, \frac{\Upsilon_{0}}{2}\right)$ & $\nu_{0}=6 ; \Upsilon_{0}=0.01$ \\
\hline
\end{tabular}

Estimation of the parameters of (2) can be accomplished by data augmentation (Tanner and Wong, 1987). Define a latent variable, $y_{i m}$, which has mean $\alpha_{i 0}+\alpha_{i q} \mathbf{q}_{m}+\alpha_{i w} \mathbf{w}_{m}$, unit variance, and is restricted such that $y_{i m}>0$ iff $P_{i m}=1$. Then, conditional on $\alpha_{i}$, $y_{i}=\left\{y_{i m}\right\}_{m=1}^{M}$ can be drawn independently from truncated normal distributions. Let $\mathbf{q}=$ $\left(q_{1}, \ldots, q_{M}\right)^{\prime}$ and $\mathbf{w}=\left(w_{1}, \ldots, w_{M}\right)^{\prime}$. Then, conditional on the drawn $y_{i m}$, we draw $\alpha_{i}$ from a normal posterior as follows:

$$
\alpha_{i} \mid y_{i} \sim N\left(\mathbf{a}_{i}, \mathbf{A}_{i}\right)
$$

where $\mathbf{a}_{i}=\left(\mathbf{A}_{0}^{-1}+\mathbf{X}_{i}^{\prime} \mathbf{X}_{i}\right)^{-1}, \mathbf{a}_{i}=\mathbf{A}_{i}\left(\mathbf{A}_{0}^{-1} \mathbf{a}_{0}+\mathbf{X}_{i}^{\prime} \mathbf{y}_{i}\right), \mathbf{y}_{i}=\left(y_{i 1}, \ldots, y_{i M}\right)^{\prime}$, and $\mathbf{X}_{i}=$ $\left(\mathbf{1}_{M}, \mathbf{q}, \mathbf{w}\right)$. After a suitable number of draws are discarded to obtain convergence, we use the draws of the $\alpha_{i}$ to generate predictions for performance of the $N$ loans to be used for 
underwriting. For each draw, we compute $\widehat{\mathbf{P}}_{n}$ and $\widetilde{\mathbf{P}}_{n}$ from (3) and (6), respectively. ${ }^{17}$

For each (post-convergence) draw of $\widehat{\mathbf{P}}_{n}$, we sample 1,000 draws from the posterior distributions of the model parameters $\beta_{-p}, \beta_{p}, \gamma, \delta$, and $\sigma^{2}$. Conditional on $\delta$ and $\sigma^{2}$, the model inclusion parameters, $\gamma$, and the vector of slopes (excluding $\beta_{p}$ ), $\beta_{-p}$, can be drawn jointly from a reversible-jump Metropolis-Hastings-in-Gibbs step (see Troughton and Godsill, 1997, and Holmes and Held, 2006). ${ }^{18}$ The joint move uses a proposal density of the form

$$
q\left(\gamma^{*}, \beta_{-p}^{*} ; \gamma, \beta_{-p}\right)=p\left(\beta^{*} \mid \gamma^{*}, \beta_{-p}\right) q\left(\gamma^{*} \mid \gamma\right)
$$

which means we draw the candidate $\gamma^{*}$ first and then, conditional on $\gamma^{*}$, we draw $\beta_{-p}^{*}$. The candidate $\gamma^{*}$ is generated by drawing a random index from a discrete uniform distribution. The element corresponding to the drawn index is switched - 1 to 0,0 to 1 . Then, conditional on $\gamma^{*}$, the prior for $\beta_{-p}$ is

$$
\beta_{-p}^{*} \sim N\left(\mathbf{b}_{0}^{*}, \mathbf{B}_{0}^{*} \mid \gamma^{*}\right)
$$

where $\mathbf{b}_{0}^{*}$ and $\mathbf{B}_{0}^{*}$ are the hyperparameters corresponding to the candidate covariate set. The candidate $\beta^{*}$ is drawn from

$$
\beta_{-p} \sim N\left(\mathbf{b}^{*}, \mathbf{B}^{*} \mid \gamma^{*}\right)
$$

with parameters

$$
\mathbf{b}^{*}=\mathbf{B}^{*}\left(\mathbf{B}_{0}^{*-1} \mathbf{b}_{0}^{*}+\sigma^{-2} \zeta^{\prime} \mathbf{R}\right)
$$

and

\footnotetext{
${ }^{17}$ The benchmark model sets $\delta \equiv 0$ such that we do not make use of $\tilde{\mathbf{P}}_{n}$.

${ }^{18}$ Turning elements of the indicator $\gamma$ on and off changes the model dimension. The resulting variation in the model dimension across Gibbs iterations makes joint sampling more efficient.
} 


$$
\mathbf{B}^{*}=\left(\mathbf{B}_{0}^{*-1}+\sigma^{-2} \zeta^{\prime} \zeta\right)^{-1}
$$

where $\mathbf{R}=\left(R_{1}-\beta_{p}\left(\delta \widehat{\mathbf{P}}_{1}-(1-\delta) \widetilde{\mathbf{P}}_{1}\right), \ldots, R_{N}-\beta_{p}\left(\delta \widehat{\mathbf{P}}_{N}-(1-\delta) \widetilde{\mathbf{P}}_{N}\right)\right)^{\prime}, \zeta_{n}=\left(1, \mathbf{z}_{n}^{\prime}, \mathbf{x}_{n}^{\prime}\right)^{\prime}$, and $\zeta=\left(\zeta_{1}, \ldots, \zeta_{N}\right)$. We accept the joint draw $\left[\gamma^{*}, \beta_{-p}^{*}\right]$ with probability

$$
\Pi=\min \left\{1, \frac{\left|\mathbf{B}_{0}\right|^{1 / 2}}{\left|\mathbf{B}_{0}^{*}\right|^{1 / 2}} \frac{\left|\mathbf{B}^{*}\right|^{1 / 2}}{|\mathbf{B}|^{1 / 2}} \frac{\exp \left(\frac{1}{2} \mathbf{b}^{*} \mathbf{B}^{*-1} \mathbf{b}^{*}\right)}{\exp \left(\frac{1}{2} \mathbf{b B}^{-1} \mathbf{b}\right)}\right\},
$$

where the unstarred $\mathbf{b}, \mathbf{B}$, and $\mathbf{B}_{0}$ correspond to the hyperparameters computed conditional on the last (accepted) iteration of $\gamma$.

Next, we draw the joint pair $\left(\delta, \beta_{p}\right)$ by again selecting a candidate $\delta^{*}$ and drawing $\beta_{p}^{*}$ from a normal proposal, conditional on $\delta$. The proposals for $\delta$ and $\beta_{p}$ - as well as the acceptance probability - have forms similar to those expressed above. For brevity, we omit the formalities.

The final step in the Gibbs loop is the draw of $\sigma^{2}$ conditional on $\beta_{-p}, \beta_{p}, \gamma, \delta$, and the data. Given the prior, the innovation variance can be drawn from the inverse gamma posterior

$$
\sigma^{-2} \mid \gamma, \delta, \beta, \mathbf{R} \sim \boldsymbol{\Gamma}\left(\frac{\nu_{0}+N}{2}, \frac{\Upsilon_{0}+\mathbf{e} / \mathbf{e}}{2}\right)
$$

where $\mathbf{e}=\mathbf{R}-\beta \zeta$ and $\zeta=\left(\mathbf{1}_{N}, \delta \widehat{\mathbf{P}}_{N}-(1-\delta) \widetilde{\mathbf{P}}_{N}, \mathbf{z}_{N}^{\prime}, \mathbf{x}_{N}^{\prime}\right)^{\prime}$ 
B: Summary Statistics 


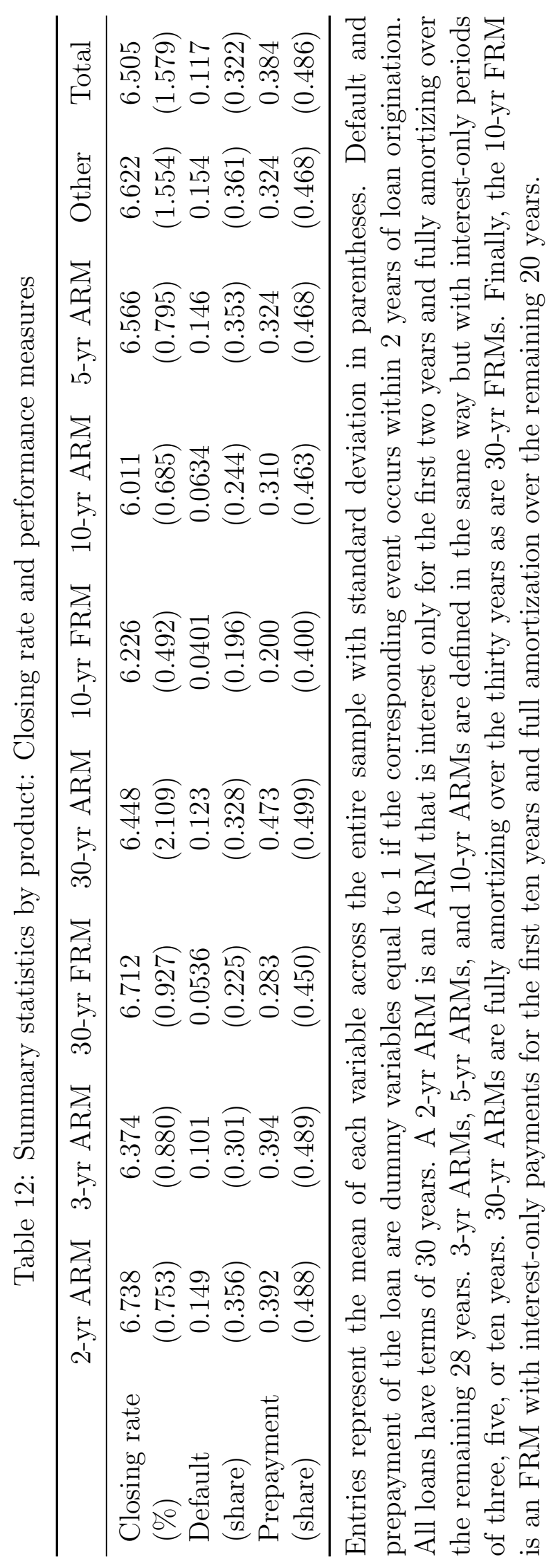




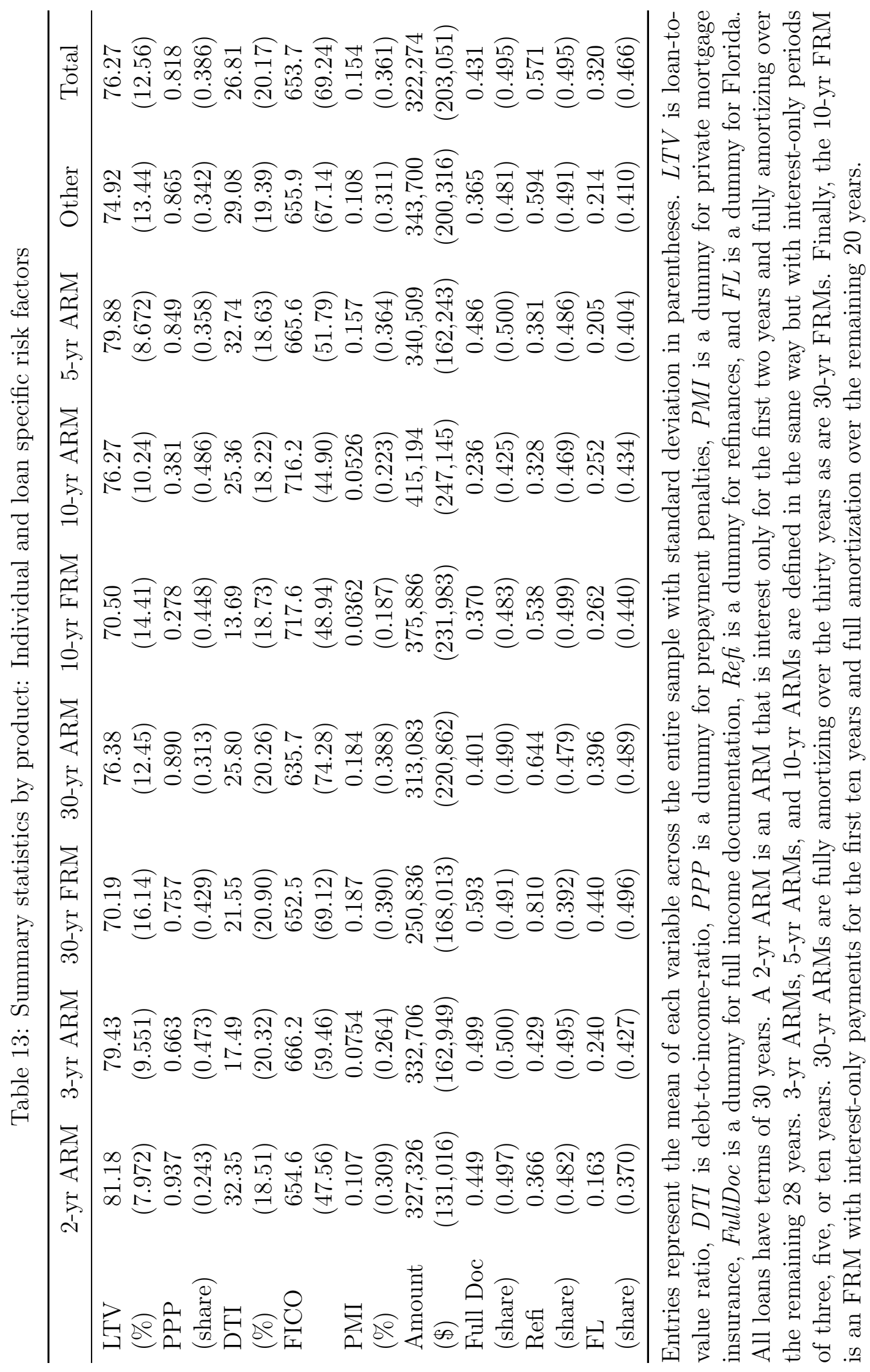




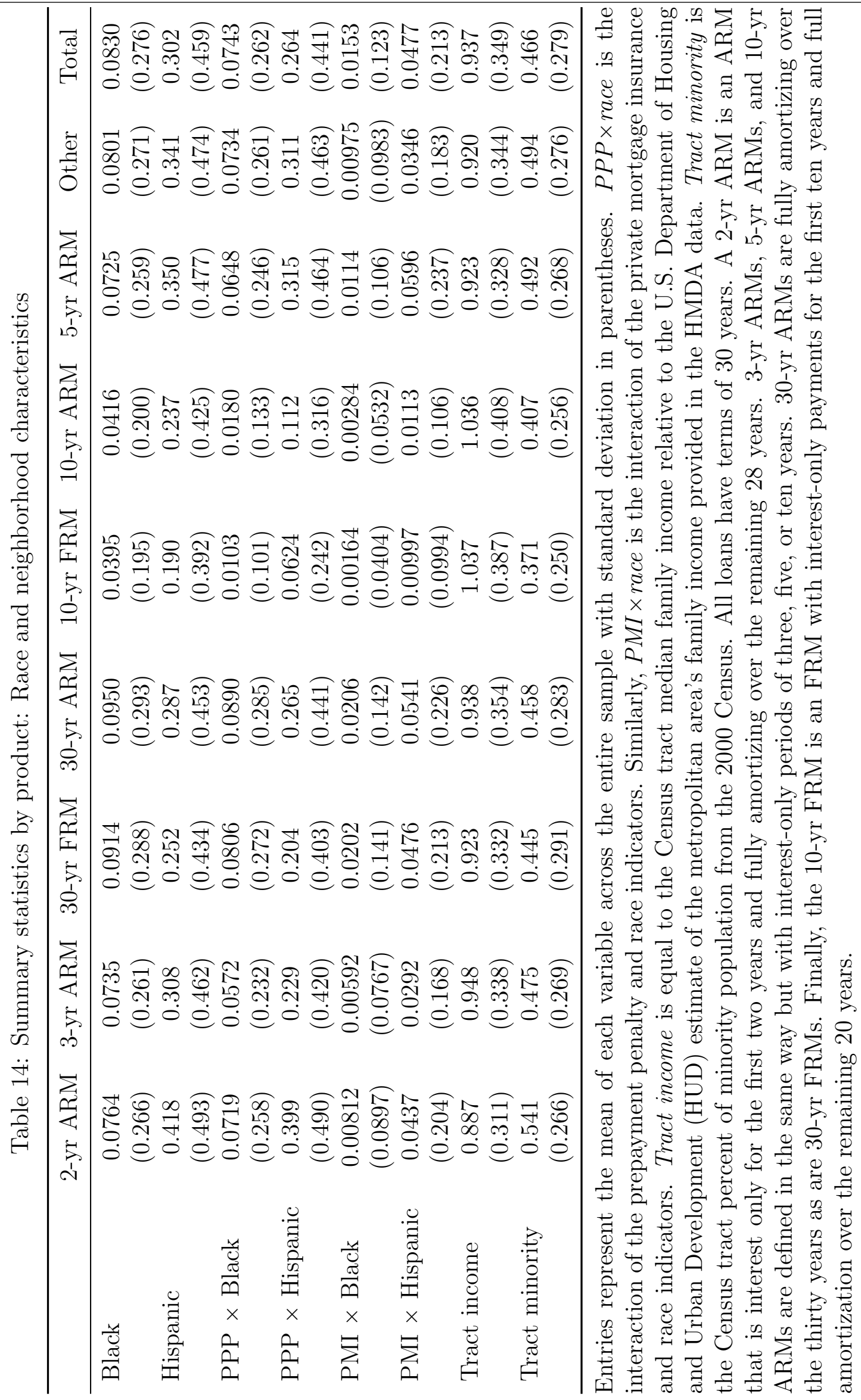

